\title{
Fronteras centroamericanas y movilidad en 2020. Una región de fracturas y desigualdades impactada por el COVID-19
}

\section{Central American borders and mobility in 2020. A region of fractures and inequalities impacted by COVID-19}

Delphine Marie Pruniera* (D) https://orcid.org/0000-0001-6870-8943

Sergio Salazar ${ }^{b}$ (D) https://orcid.org/0000-0003-2623-1125

\footnotetext{
${ }^{a}$ Universidad Nacional Autónoma de México, Instituto de Investigaciones Sociales, Ciudad de México, México, correo electrónico: prunier.delphine@sociales.unam.mx

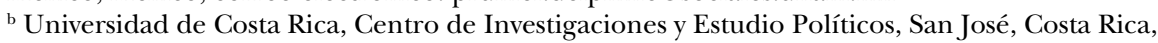
correo electrónico: sergio.salazar_a@ucr.ac.cr
}

\section{Resumen}

El artículo presenta una mirada regional sobre los efectos de la pandemia por COVID-19 en 2020, con énfasis en las medidas estatales desplegadas por

Recibido el 15 de octubre de 2020 Aceptado el 10 de junio de 2021. Publicado el 24 de junio de 2021.

*Autora para correspondencia: Delphine Prunier. Correo electrónico: prunier.delphine@sociales.unam.mx

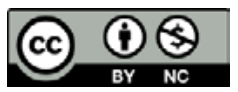

Esta obra está protegida bajo una Licencia Creative Commons Atribución-NoComercial 4.0 Internacional. los gobiernos centroamericanos y a sus impactos. Recupera elementos clave de la historia socio-territorial de la región y, a partir de una descripción de las dinámicas fronterizas y de movilidad en el contexto de pandemia, se identifican algunos puntos de análisis prioritarios para proponer futuras líneas de reflexión académica sobre la región. La argumentación se fundamenta tanto en fuentes académicas como noticiosas y otros insumos de sistematización por organizaciones sociales que han surgido al calor de la crisis. Se concluye que los efectos de la pandemia en las fronteras y en las dinámicas de circulación deberán ser interpretados en futuros trabajos a la luz de conflictos y clivajes históricos de larga data en la región, con énfasis en las relaciones aporéticas entre democracia-autoritarismo, acumulación-despojo y movilidad-control.

Palabras clave: Centroamérica, fronteras, movilidad, migración, COVID-19.

\section{Abstract}

The article presents a regional perspective on the effects of the COVID-19 pandemic in 2020, with emphasis on the state measures deployed by Central American governments and their impacts. Recovering key elements of the socio-territorial history of the region, and based on a description of border and mobility dynamics in the context of the pandemic, some priority points of analysis are identified in order to propose future lines of academic reflection on the region. The argumentation is based on both academic and news sources and other

CÓMO CITAR: Prunier, D. M. \& Salazar, S. (2021). Fronteras centroamericanas y movilidad en 2020. Una región de fracturas y desigualdades impactada por el COVID-19 [Central American borders and mobility in 2020. A region of fractures and inequalities impacted by COVID-19]. Estudios Fronterizos, 22, e073. https://doi.org/10.21670/ref.2110073 
systematization inputs by social organizations that have emerged in the heat of the crisis. It is concluded that the effects of the pandemic on borders and circulation dynamics should be interpreted in future works in the light of long-standing conflicts and historical cleavages in the region, with emphasis on the aporetic relations between democracy-authoritarianism, accumulation- dispossession and mobility-control.

Keywords: Central America, borders, mobility, migration, COVID-19.

\section{Introducción}

Centroamérica se ha convertido recientemente en un foco de atención para México, a raíz del aumento en los flujos migratorios que atraviesan el país, de su mediatización y del lugar que se les ha dado en el contexto de tensión geopolítica con los Estados Unidos. México ha volteado su mirada hacia el Sur, al tomar conciencia de la reconfiguración de su papel como país de tránsito en el corredor migratorio global. Muy frecuentemente se considera a Centroamérica como una región en crisis, cuya población víctima de pobreza y violencia huye masivamente en dirección a Estados Unidos. Sin embargo, la región centroamericana se caracteriza por fuertes contrastes y dinámicas internas propias en términos territoriales y migratorios, por lo que los movimientos internos - de tipo Sur-Sur- son centrales en los procesos de reproducción y sobrevivencia.

Si bien la pandemia de 2020 ha transformado abruptamente la región, como ha ocurrido en todo el planeta, se resaltan aquí posibles impactos del COVID-19 en las dinámicas fronterizas intrarregionales y en su conexión con dinámicas hemisféricas y globales. Durante los primeros meses de la coyuntura resultan comunes las respuestas estatales de contención de la pandemia orientadas por lógicas nacionalistas y de securitización, en el marco de lo cual las acciones de cierre de fronteras y restricciones a la movilidad transfronteriza tienen efectos particularmente evidentes para las poblaciones migrantes, solicitantes de asilo y en tránsito, pero no así para la circulación de mercancías, lo que configura un "estado de excepción de facto en materia migratoria", que se ha traducido en cierres de fronteras e hipervigilancia estatal (Castro, 2020). Las disposiciones gubernamentales de los países sobre los flujos migratorios han coincidido en tiempos y forma, y la mayoría han estado fundamentadas en declaratorias de estados de excepción o emergencia, y muestran tendencias que han sido caracterizadas como agudización de nacionalismos selectivamente xenófobos, espirales de violencia social y estatal, violación a derechos humanos, creación de espacios de confinamiento y procesos de movilidad en reversa (Álvarez Velasco, 2020a).

El objetivo de este artículo es describir las primeras etapas de la coyuntura de crisis sanitaria en 2020, específicamente en relación con las respuestas estatales y gubernamentales, como forma de atraer la atención sobre la dimensión compleja y diversa de la reconfiguración del espacio centroamericano y de sus líneas de fractura histórica. Diversos trabajos académicos (Granados Chaverri, 1986; Morales Gamboa, 2005, 2015) han mostrado que Centroamérica, lejos de ser una región homogénea, cuenta con países, mercados laborales, regímenes políticos y dinámicas demográficas distintas, que dibujan límites, desequilibrios y fronteras dentro de la región y no siempre en coincidencia con las del Estado-nación. Proponemos que los actuales y futuros impactos del COVID-19 no se pueden comprender sin tomar en cuenta la construcción histórica y territorial del istmo y las movilidades que lo atraviesan. Como 
lo plantea Abelardo Morales Gamboa (2015, p. 19), "la condición subordinada y periférica de la región en el sistema hemisférico, dominado por Estados Unidos, y el carácter altamente conflictivo, contradictorio y fragmentado, tanto desde el punto de vista territorial como socio político y cultural", son elementos primordiales a la hora de entablar una lectura de las dinámicas territoriales y políticas que estructuran la región centroamericana.

Como telón de fondo a la descripción planteada, se supone una imbricación histórica de lógicas de apertura —exclusión, liberalismo económico-, autoritarismo político, frenos a la migración —aceleración de la circulación de capitales, flujos-, enclaves, que, lejos de ser contradictorias, conforman la base de los modelos de desarrollo para una región plenamente imbricada en el capitalismo globalizado. Por lo tanto, en esta contribución se apunta a describir algunos elementos centrales en la forma en que la gestión estatal y social de la pandemia impactan diversas categorías de frontera, es decir, se consideran distintas escalas (nacional, regional e internacional), y también diferentes tipos de límites o asimetrías, sean espaciales, productivos, laborales o sociales.

A nivel metodológico, el artículo se fundamenta en información empírica recabada sobre todo de fuentes periodísticas, gubernamentales y de algunas organizaciones sociales y no gubernamentales. Se han utilizado periódicos y medios de comunicación nacionales con presencia digital, así como las páginas de gobiernos y organizaciones. Adicionalmente, se han consultado diversas iniciativas que, desde el inicio de la pandemia, han apuntado a sistematizar y analizar, desde un plano académico internacional, la coyuntura crítica. Dado que el artículo fue elaborado en medio del contexto de pandemia y su evolución permanente y compleja, su alcance es fundamentalmente descriptivo, apunta a identificar algunas posibles líneas de análisis a futuro que se puedan establecer en el marco de la historicidad de la región. Se espera con esta contribución enfrentar el desafío de articular un análisis de los mecanismos tradicionales de movilidad y territorios circulatorios en esta región del Sur (Baby-Collin et al., 2009; Mitchell, 1985; Prothero \& Chapman, 1985; Simon, 2008; Tarrius, 2000), con una lectura más inmediata de la emergencia de nuevas lógicas que podrían transformar, en este inicio de la década 2020, la geopolítica regional, las asimetrías socioterritoriales, las estrategias de resistencia y de transgresión de las fronteras (De Genova, 2017).

El artículo se estructura en tres partes. Primero, se ofrece un panorama de las migraciones regionales enfocada a la profundidad histórica de las dinámicas internas de frontera, para un mejor entendimiento de los mercados laborales, configuraciones demográficas y conflictos políticos que han modelado el espacio y las movilidades regionales en las últimas décadas. En un segundo momento, se presentan los diferentes efectos de la coyuntura en las fronteras centroamericanas y en la (in)movilidad de su población, a partir de la descripción de las distintas medidas de cierre y control que se han implementado en los diferentes países y de sus impactos en varios tipos de flujos, entre marzo de 2020 y enero de 2021. En tercer lugar, se exploran las posibles consecuencias de la pandemia para las sociedades y economías centroamericanas, en particular desde la perspectiva del aumento de la pobreza, del nivel de injusticias y de violencia estructural. Se entrevé la posibilidad de nuevos fenómenos de desafío al régimen global de las fronteras y una profundización de las causas de expulsión migratoria hacia el Norte. 


\section{Permeabilidad histórica de las fronteras internas}

\section{Lógicas agrarias, estructuración territorial por la agricultura y los movimientos de mano de obra}

Las movilidades regionales han estado históricamente relacionadas con las dinámicas agrarias y el avance de la frontera agrícola. Desde el siglo xıx, la creciente importancia de los cultivos de exportación con destino al mercado global —en particular el café, plátano, cacao, caña de azúcar- ha estructurado profundamente el ordenamiento territorial de la región (Baumeister, 1994; Demyk, 2007), desde un modelo económico orientado hacia el exterior y una organización socio-política profundamente marcada por el control de dos recursos fundamentales: la tierra y la fuerza de trabajo. Los movimientos de población estuvieron, por lo tanto, estrechamente articulados con las distintas etapas de reforma agraria, de colonización y de valorización de tierras consideradas como "vacías". Muy a menudo, la presión sobre la tierra se combinó con tensiones sociales en contextos de concentración en manos de fincas exportadoras y de expulsión de poblaciones campesinas. En Guatemala, por ejemplo, durante el periodo colonial, la instalación de plantaciones de cacao o de caña produjo muy a menudo desplazamientos forzados y, después de la independencia de 1821, los latifundios fueron fundamentales en la continuidad y profundización de las desigualdades. Estas migraciones jornaleras desde las tierras altas siguen marcando al día de hoy fronteras espaciales, económicas y sociales claves, tanto a nivel nacional como transfronterizo, hacia las fincas de Chiapas en México (Angulo Barredo, 2008; Martínez Velazco, 1993).

El caso de El Salvador también es muy relevante, con una etapa de fuertes movimientos migratorios que cruzaron la frontera nacional hacia Honduras en búsqueda de tierras (León \& Salazar, 2016). El crecimiento demográfico, la densidad poblacional, la tradición de movilidades temporales y la desigualdad en la repartición agraria en ese país llevaron a un gran número de familias campesinas a instalarse y colonizar tierras en el sur de Honduras: en 1960, 12\% de la población salvadoreña se encontraba en el país vecino (Faret, 2015). Es importante notar que este proceso generó altos niveles de tensión entre los dos países (guerra de 100 horas o guerra del fútbol en 1969), ya que el fenómeno fue instrumentalizado por las elites políticas y económicas que prefirieron voltear la atención y generar odio xenófobo hacia los jornaleros y colonos salvadoreños para evitar una reforma agraria más equitativa en su país.

Altamente dependientes del comercio global y enfocados a la agricultura intensiva como ventaja comparativa, los territorios centroamericanos se han organizado en gran medida en relación con la evolución de estos monocultivos. Este sector generó desplazamientos de población en diferentes momentos del siglo pasado, ya fuera de manera duradera (instalación y colonización, con avance de fronteras agrícolas, como en el caso del banano en Honduras, del café o del ganado en Guatemala y Nicaragua, por ejemplo) (Baumeister, 2001; Euraque, 1996; Pérez Brignoli \& Samper, 1994), o bien con flujos de movilidades temporales y circulatorias, en mercados laborales específicos y segmentados, como el caso emblemático de los jornaleros nicaragüenses en las fincas de café o los campos de piña costarricenses (Rodríguez Echavarría \& Prunier, 2020). 


\section{Mercados laborales y movilidades regionales}

Más allá del sector agrícola, las movilidades laborales contribuyen a estructurar los territorios centroamericanos, dibujando fronteras y espacios productivos desiguales. Por un lado, los polos urbanos atraen trabajadores nacionales u originarios de países vecinos, para los cuales el cruce de la frontera forma parte de la lógica de extensión del mercado laboral y de diversificación de las actividades y espacios productivos. Se trata de trabajadores que se integran en los sectores de la economía urbana informal, del servicio doméstico, de las obras públicas o de la construcción, bajo lógicas de movilidad que pueden implicar instalaciones de larga duración (con el conjunto o parte del grupo doméstico), o bien circulaciones migratorias con retornos frecuentes al lugar de origen (Prunier, 2017). Cabe subrayar aquí tres aspectos importantes de estas movilidades laborales a escala regional. Primero, la importancia de las movilidades femeninas para actividades de cuidado o de trabajo doméstico que implican tanto movimientos del campo hacia las ciudades como cruces de fronteras nacionales. Segundo, el papel de los megaproyectos en la movilización de mano de obra temporal —esencialmente masculina - en sitios que requieren grandes cantidades de trabajadores por periodos establecidos, por ejemplo para la edificación de complejos turísticos o para la construcción de grandes planes de infraestructuras de transporte y comunicación (como en el Golfo de Fonsecal) (Morales Gamboa et al., 2011). Finalmente, existe una migración de reemplazo o de relevo en los sectores laborales menos atractivos (físicamente laboriosos, con condiciones precarias y salarios bajos), con empleos cubiertos por los grupos más vulnerables y dispuestos a migrar. Este fenómeno se observa sobre todo desde la década de 1990, por ejemplo en Costa Rica, debido al aumento del nivel escolar de la población y la creciente incorporación de las mujeres al mercado laboral, o también en El Salvador, donde la masiva migración hacia Estados Unidos y la importancia de la recepción de remesas en la economía familiar han llevado a una deserción de la fuerza de trabajo nacional de los trabajos más pesados (Cañada, 2011).

\section{Conflictos armados y violencia, refugio y contrainsurgencia}

En Centroamérica, los espacios fronterizos intrarregionales han jugado un papel central durante los conflictos armados, tanto en el contexto de los desplazamientos forzados como de las relaciones de poder de la Guerra Fría que se expresaban a escala de la geopolítica regional.

En Guatemala, la larga guerra civil que marcó casi toda la segunda mitad del siglo xx provocó situaciones de terror y de violencia extrema que llevaron a desplazamientos dentro de las fronteras nacionales, pero también importantes flujos de refugiados en los países vecinos (Honduras, México, Belice) y en Estados Unidos. En El Salvador y Nicaragua, los conflictos armados que empezaron desde los años de 1960 y terminaron solamente hasta el inicio de la década de 1990, fueron responsables

\footnotetext{
${ }^{1}$ Construcción de puerto y carreteras para el proyecto de corredor transoceánico hacia la costa del Caribe en el marco del Proyecto Mesoamérica, en una interfaz trinacional en Honduras, El Salvador y Nicaragua (Medina, 2013).
} 
de muertes, enfrentamientos, violencias paramilitares, situaciones de crisis económica y de pobreza que obligaron a decenas de miles de personas a cruzar las fronteras en búsqueda de protección y de empleo. Honduras, punto estratégico de presencia militar estadounidense en la región, "protegido" de los movimientos revolucionarios, y Costa Rica, país neutral en la confrontación entre los dos bloques y economía en fuerte crecimiento, constituyeron los dos principales territorios de acogida de personas refugiadas. Durante la "década perdida" de los años de 1980 (marcada por violencia armada, inestabilidad política y bajo nivel de desarrollo económico), Honduras fue un país de recepción más que de expulsión. Además, las zonas transfronterizas fueron espacios clave de la confrontación ideológica global de la época, que estructuraron líneas de oposición política fuertes entre los diferentes países de la región. A partir de 1985, la zona sur de Honduras se transformó en una plataforma estratégica para la política anticomunista estadounidense, con la instalación de bases de entrenamiento y apoyo logístico a los Contras nicaragüenses.

Es preciso hacer énfasis en las raíces históricas de la migración centroamericana hacia Estados Unidos, que se ha relacionado tanto con el contexto de violencia civil en distintos países de la región y de huida de importante número de refugiados, como con la situación de profunda vulnerabilidad económica que experimentaron estas poblaciones, y más actualmente con la violencia social vinculada al crimen organizado (Farah, 2012, Sampó, 2013). La inserción de estos trabajadores migrantes en los mercados laborales estadounidenses generó la formación de importantes comunidades transnacionales que tejieron redes sociales y culturales sólidas, cuyo papel es notorio en las dinámicas más recientes de migración internacional hacia el Norte, particularmente visibilizadas con las "caravanas" de 2018, pero que se intensificaron desde la primera década de 2000, a partir del agravamiento de la pobreza, la exclusión social y el deterioro ambiental en la región (Eguren \& Hernández Bonilla, 2019).

\section{Cruce de fronteras por migrantes extracontinentales en camino hacia el Norte}

La región centroamericana representa hoy en día una zona crítica en el corredor migratorio transamericano (Álvarez Velasco, 2016; Armijo Canto \& Benítez Manaut, 2016). La existencia de nuevos contingentes conformados por migrantes extracontinentales originarios de África, Haití, Cuba y Asia (con conexiones en Brasil, Colombia y Ecuador) ha provocado debates emergentes en México sobre su posición y papel como país de tránsito, en el contexto de las políticas de externalización de la frontera sur de Estados Unidos (Varela, 2015; Garibo, 2016). Se insiste aquí en el impacto de estos corredores en la reconfiguración de las lógicas fronterizas en Centroamérica. Por un lado, la presencia de estos flujos que atraviesan la región en dirección al norte constituye un fenómeno nuevo que obliga a los diferentes países a definir políticas migratorias diferenciadas (de control, asistencia humanitaria, salvoconducto, etcétera). Por otro lado, vemos que Centroamérica se posiciona en la articulación intercontinental de las movilidades humanas, lo que demuestra una vez más la interdependencia entre sistemas migratorios (suramericanos, africanos, norteamericano) y el rol clave de la región en la geopolítica de la gestión global de las movilidades humanas (Álvarez Velasco, 2016). 


\section{Cierre y control en las fronteras centroamericanas durante la epidemia de COVID-19: impactos sociales y territoriales}

\section{Control policial-militar, estigmatización y discriminación}

El contexto de emergencia sanitaria ha puesto de relieve conflictos, contradicciones y formas de violencia estructural (Bourgois, 2009; Galtung, 1969) que han marcado la historia de la región y sus formaciones nacionales (véase Tabla 1). Conflictos fronterizos anteriores hacen surgir tensiones e incluso expresiones de violencia social e institucional por los gobiernos en sus desafíos por coordinar las medidas de contención y afectaciones derivadas de estas. Políticas y discursos gubernamentales nacionalistas, expresiones de xenofobia y discriminación, constantes amenazas de deportación, limitación en el acceso a bienes y servicios y formas de protección social son condiciones históricas que se actualizan ante la situación de emergencia que afectan de forma particularmente grave a las poblaciones más vulnerables. Una tendencia común en varios de los países de la región respecto a la atención de la pandemia es el incremento en las medidas de vigilancia, control y presencia militar-policial en las zonas fronterizas. Esto ha implicado tanto una intensificación de algunas tensiones históricas en estas zonas, como un agravamiento en las condiciones de movilidad y estancia de poblaciones migrantes vulnerabilizadas.

En Costa Rica, el cierre de fronteras iniciado el 18 de marzo de 2020 (operativo "Fronteras Seguras") significó el rechazo de más de 5000 personas extranjeras en la frontera norte solo en el primer mes de su ejecución (Murillo, 2020), y cerca de 16000 para principios de julio (Pomareda, 2020a). ${ }^{2}$ En la frontera sur con Panamá, la situación fue más grave para población migrante extracontinental que utiliza esta ruta para llegar a Estados Unidos, como el caso de un grupo de migrantes de Bangladesh que fue detenido por autoridades migratorias a mediados de julio, e ingresado a un centro de detención de la Dirección de Migración y Extranjería (Pomareda, 2020b).

En la frontera norte "la vigilancia extrema (...), las detenciones y la identificación de focos de contagio en empacadoras y fincas agrícolas donde trabajan migrantes nicaragüenses también ha desatado una reacción xenofóbica por parte de amplios sectores de la población" (Pomareda, 2020a). Si bien el manejo de la pandemia por el gobierno nicaragüense ha sido señalado por diversas instancias internacionales como insuficiente e incluso irresponsable y riesgoso (ops reitera advertencias a Nicaragua sobre manejo de la pandemia, 2020; AFP, 2020; Wallace, 2020), esto ha despertado en Costa Rica discursos oficiales y sociales de tono nacionalista y securitario, que generan condiciones para el aumento en la xenofobia y la discriminación (Chavarría, 2020).

La pandemia ha justificado una perversa intersección entre políticas de salud pública y control a la movilidad en distintos espacios nacionales de las Américas. Esto ha exacerbado el sentido común construido desde el Estado y los medios de comunicación que asocia la figura del extranjero con la "peste". Así, de manera generalizada, los migrantes — más aún si están irregulares— son vistos como una

\footnotetext{
${ }^{2}$ Posteriormente, el gobierno de Costa Rica amplió el periodo de cierre de fronteras hasta el 1 de agosto, y a partir del 2 de agosto permitió el ingreso al territorio de personas extranjeras bajo categoría migratoria de residentes o subcategoría de turismo, únicamente por vía aérea.
} 
amenaza a la sanidad pública por ser supuestos vectores de contagio. A la vez, en medio del colapso económico, la figura del extranjero es percibida como una "carga social” particularmente para los Estados receptores (Álvarez Velasco, 2020b; Chacón, 2020a; Pomareda, 2020a). ${ }^{3}$

Estas situaciones estuvieron, además, acompañadas de brotes de violencia social como los descritos antes, y con una afectación directa para poblaciones vulnerables en términos de su acceso a la salud y otras formas de protección. Esto ha implicado una afectación en la contención de la propagación del virus que no solo no respeta fronteras o puestos militares, sino que además se ve agravada por las condiciones que surgen producto del rechazo y la desatención.

Un claro ejemplo de estas contradicciones fue la medida del gobierno costarricense, a finales de mayo, de exigir la presencia de policías y agentes migratorios como requisito para atender a población extranjera en puestos de salud locales. Aunque fue una disposición de las autoridades locales de salud (Los Chiles), contó con el respaldo del gobierno central; la medida estableció que "para todo paciente indocumentado, se deberá realizar llamada inmediata al despacho de Migración y Fuerza Pública”, y que no se atendería a las personas hasta que no se contará con la presencia de estas instancias (Ugarte, 2020b).

Otra población afectada por las medidas de contención fue la comunidad refugiada o solicitante de refugio. En balance general para la región latinoamericana es posible afirmar que, si bien las medidas oficiales han sido diversas, la tendencia es que las respuestas sean "limitadas, reducidas, y no han procurado extender el derecho al asilo y al refugio para la gran mayoría de solicitantes", además de que se redujo "el número de reconocimientos [...] para transferir ese proceso a terceros países poniendo en abierto riesgo este derecho humano universal" (Álvarez Velasco, 2020c).

En el caso costarricense, uno de los países con mayor tasa de población refugiada en la región (Gatica López, 2018), las medidas de cierre o virtualización de instituciones y servicios, tanto gubernamentales como no gubernamentales, generaron nuevos riesgos y condiciones de vulnerabilidad que se sumaron a las ya conocidas: desempleo, falta de vivienda, barreras de acceso a servicios de salud y la imposibilidad de volver a Nicaragua por la situación política y el cierre de fronteras (Muñoz, 2020). Gracias a un convenio previo entre la Caja Costarricense de Seguridad Social y el Alto Comisionado de las Naciones Unidas para los Refugiados (ACNUR), se continuó financiando el seguro médico de 6000 personas refugiadas y solicitantes de refugio, ahora con prioridad a personas con padecimientos de salud y situación de precariedad económica (ACNUR, 2020). No obstante, esto no fue suficiente para resguardar la estabilidad al conjunto de esta población, por lo que, ante el limbo jurídico por la disminución en la gestión de ciertas instituciones producto de la virtualización del trabajo, así como por la suspensión en el otorgamiento de la condición de refugio, ${ }^{4}$ alrededor de 1200 personas nicaragüenses abandonaron sus solicitudes y tuvieron que regresar a su país.

\footnotetext{
${ }^{3}$ Ante este contexto, también han surgido respuestas desde la sociedad civil organizada, que enfrentan el discurso xenofóbico y reducidamente sanitario, al exigir una reorientación de las respuestas estatales, en la línea de garantizar derechos a poblaciones vulnerabilizadas.

${ }^{4}$ Resolución N DJUR-043-03-2019-JM. https://migracion.go.cr/Documentos\%20compartidos/Otros/RESOLUCION\%20MEDIDAS\%20ADMINISTRATIVAS\%20COVID-19.pdf
} 
También Honduras decidió reforzar el control en su frontera con Nicaragua a mediados de mayo. Se hizo especial énfasis en la "irresponsabilidad" del gobierno nicaragüense que, además de no haber tomado medidas de contingencia o cierre de fronteras nacionales, se encontraba en una postura de negación de la pandemia y hasta organizaba eventos masivos ("Amor en tiempos del COVID-19. Caminamos como pueblo con fe, vida y esperanza", en marzo de 2020) (véase Collombon, 2020). Además de que, debido a las medidas implementadas por el gobierno, la mayoría de las instituciones estatales y privadas de atención a población migrante se encontraban paralizadas, se agudizó el control sanitario y migratorio en las aduanas y se ordenó el despliegue de policías y militares en puntos ciegos de la frontera, acompañado de un discurso de estigmatización y desconfianza hacia las personas que podrían cruzar irregularmente desde un país en donde las cifras oficiales de casos COVID-19 parecían claramente subestimadas (Honduras se blinda para frenar ingreso de nicaragüenses por COVID-19, 2020).

Esto desencadenó abusos de las autoridades, al resaltar el caso de más de 80 personas migrantes irregulares en tránsito estacionadas en la frontera de Choluteca que a finales de abril, mientras estaban alojadas en hoteles, albergues de grupos religiosos, centros comunitarios y casas privadas, fueron violentadas por autoridades policiales durante un operativo de desalojo forzoso. Según un informe de varias organizaciones locales, durante el operativo también se cometieron actos de extorsión, amenaza y otras violaciones a derechos de la población estacionada, que incluía mujeres embarazadas y niños (La impaciente espera de los migrantes en Choluteca, Honduras, 2020), y que después del desalojo se vieron obligadas a dormir en la calle (Migrantes violentados por autoridades en medio de emergencia nacional, 2020).

En el caso de El Salvador, uno de los países que más tempranamente empezó a tomar medidas de cierre y control, a finales de enero las autoridades de migración implementaron medidas sanitarias en las fronteras y aeropuertos (Migración refuerza medidas sanitarias en fronteras y aeropuerto por Coronavirus, 2020), y desde finales de febrero se establecieron alrededor de cuarenta centros de vigilancia sanitaria en diferentes puntos del territorio nacional, con el fin de controlar y eventualmente detener a la población e implementar cuarentenas obligatorias. Adicionalmente, se estableció que las personas que ingresaran al país por puntos ciegos debían enfrentar cargos judiciales (Álvarez Velasco, 2020d), y para inicios de marzo se elevaron todos los controles y mecanismos de detención y seguimiento de población en puntos fronterizos (Migración refuerza medidas sanitarias en fronteras y aeropuerto por Coronavirus, 2020).

\section{Poblaciones varadas, internamientos, deportaciones y cuarentenas obligatorias}

Otro factor común en la región y en el hemisferio es la afectación en las dinámicas de movilidad transnacional, producto de las medidas nacionales y la ausencia de coordinación internacional. Particularmente, está el caso de poblaciones que quedan varadas en áreas fronterizas, o que son internadas en centros de detención en condiciones poco adecuadas.

En Costa Rica destacó el caso de más de 2600 personas migrantes de Asia, África y Haití que, a inicios de marzo llegaron desde Sudamérica con destino a Estados 
Unidos, quedaron detenidas en la frontera con Panamá. Luego de varias semanas de inmovilidad y en condiciones de detención inadecuadas, el gobierno costarricense estableció un acuerdo con el gobierno panameño para desarrollar un traslado controlado hacia la frontera norte, donde permanecerían en un centro de detención hasta que pudieran ingresar a Nicaragua con el objetivo de continuar con su tránsito hacia Estados Unidos (Peña, 2020) Sin embargo, esto no fue posible, pues además de que surgieron problemas logísticos y solo se pudo trasladar a una parte del grupo, el gobierno de Nicaragua anunció el cierre de fronteras con vigilancia militar, incluso para cordones humanitarios, por lo que la población quedó estacionada entre Costa Rica y Panamá (Miranda \& Murillo, 2020).

Uno de los puntos fronterizos donde se ha expresado de forma más cuantiosa este fenómeno es el Tapón del Darién, donde han quedado varados haitianos, cubanos, sudamericanos y migrantes extracontinentales en tránsito hacia Estados Unidos. Desde inicios de marzo el gobierno panameño cerró por completo sus fronteras al ingreso de personas, y ya para mediados de abril había más de 2000 migrantes (sobre todo de Haití, Congo, Bangladesh y Yemen) ubicadas en la Estación de Recepción de Migrantes (Mrs) "La Peñita" en la comunidad de Bajo Chiquito, y otras en la Mrs "Los Planes", en Chiriquí (Pomareda, 2020b). Las condiciones de hacinamiento, falta de alimentos, problemas sanitarios por el manejo de residuos y el aumento de cuadros de ansiedad y estrés en la población, generaron situaciones críticas que aumentaban las condiciones de riesgo en el marco de la pandemia, y mostraban que los gobiernos no solo no estaban preparados para enfrentar una situación como esta, sino que no tuvieron la capacidad para establecer medidas coordinadas y conjuntas (oIM, 2020). Este tipo de situaciones provocó denuncias de organizaciones sociales y no gubernamentales y acciones de protesta de la población migrante que mostraron gran capacidad de organización y contestación a las medidas oficiales, en procura de la garantía de sus derechos básicos. ${ }^{5}$

Justamente en la frontera norte de la región, entre Guatemala y México, se ha mostrado de forma cruda la situación de inmovilidad forzada. Para Juan Luis Carbajal, sacerdote y director de la Pastoral Movilidad Humana de la Conferencia Episcopal de Guatemala, la situación ha mostrado "una falta de respeto a las personas migrantes", pues las autoridades de ambos países "se han dado a la tarea simplemente de sacar, barrer a las personas migrantes sin importar sus condiciones de salud $[y]$ sin considerar alternativas". Esto ha significado el incumplimiento de protocolos, acuerdos y memorandos de entendimiento regionales de deportación, y el aumento en las condiciones de vulnerabilidad y riesgo de las personas deportadas. Según Carbajal, estas medidas muestran "una nueva realidad migratoria, donde el control sanitario es la justificación para el control de los migrantes y donde la estigmatización ha sido la constante" (Pomareda, 2020a).

El caso de Nicaragua es más complejo, pues si bien el gobierno no estableció restricciones de ingreso a personas extranjeras por vía terrestre o aérea, sí prohibió el

\footnotetext{
${ }^{5}$ Destaca el caso del Centro de Atención Temporal a Migrantes (Catem), en el norte de Costa Rica, donde a mediados de julio un grupo de personas migrantes detenidas provocó disturbios, incendios y bloqueos como forma de protesta por las condiciones de internamiento, y para exigir que se les permitiera continuar con su movilidad hacia el norte (Pomareda, 2020b). Según la Dirección de Migración y Extranjería de Costa Rica, hasta el 1 de julio permanecían detenidas 285 personas migrantes extrarregionales; 118 personas en la frontera norte ( 85 adultos y 33 menores de edad), y 167 en la frontera sur (109 adultos y 58 menores).
} 
regreso de cientos de personas nacionales que se quedaron sin trabajo en el exterior, sobre todo en Costa Rica, y que buscaban regresar a su país (Cajina, 2020). En Honduras, hacia finales de junio, un grupo de alrededor de 150 personas migrantes, incluidos adultos mayores, mujeres y niños, salía de la terminal de autobuses de San Pedro Sula hacia la frontera de Corinto, al noroeste del país, donde fueron detenidas por autoridades policiales y militares de ambos países y quedaron internadas en centros de detención donde tuvieron que cumplir cuarentena obligatoria. Otro grupo de alrededor de 250 personas de África, Cuba y Haití, quedó varado del lado hondureño de la frontera, y permanecía detenido en centros migratorios en Tegucigalpa y Choluteca (Pomareda, 2020a).

Por otro lado, el fenómeno de las deportaciones desde Estados Unidos agregó otro grado de complejidad al panorama regional. En Guatemala, por ejemplo, a pesar del cierre de fronteras internacionales y cancelación de vuelos, declarado el 13 de marzo, el país continuó recibiendo vuelos de deportados de Estados Unidos (más de 5162 personas), así como por vía terrestre desde México (6 522 personas) (Instituto Guatemalteco de Migración, 2020). Si bien los últimos aviones que llegaron en septiembre parecen haber transportado migrantes ya recuperados del COVID-19, el gobierno guatemalteco afirmó que Estados Unidos no había respetado los protocolos sanitarios en distintos vuelos durante marzo, por lo que entre $50 \%$ y $75 \%$ de las personas que los ocupaban regresó contagiado de COVID-19 (El Faro/AFP, 2020). Esta situación generó preocupación en las asociaciones de defensa de los derechos de los migrantes (Equipo de Reflexión, Investigación y Comunicación ERIC-SJ, 2020), y un clima de sospecha y rechazo hacia estas personas, sin duda relacionado con las declaraciones del mismo presidente que habló del "vuelo maldito" (Reyes, 2020).

En el caso de El Salvador, las deportaciones se reanudaron también el 24 de marzo, justo después de que "el Departamento de Seguridad Nacional de los Estados Unidos presionara a los gobiernos del Triángulo Norte para que levantaran sus cuarentenas en los aeropuertos para admitir el arribo de los migrantes deportados" (Cáceres et al., 2020). Según Ovidio González, director de la organización Tutela Legal Dra. María Julia Hernández, el mismo gobierno contribuyó a su estigmatización y vulnerabilidad, les llamaban "los infectados", y desde el principio se determinó que no se iba a permitir su ingreso al país. Para César Ríos, director del Instituto Salvadoreño del Migrante (Insami), esto ha implicado un cambio en el ciclo de retorno, pues ahora no solo son detenidos por meses en los centros migratorios en el país del norte, sino que al regresar vuelven a ser encerrados; "el luto migratorio en esta nueva realidad se extiende, y después de estar en un encierro transnacional, están viniendo a estar en un encierro nacional" (Pomareda, 2020a). ${ }^{6}$

\section{Impactos en sectores económicos dependientes de la mano de obra migrante}

Como se ha argumentado en la primera parte, la realidad de la región centroamericana da cuenta de una migración regional transfronteriza histórica, asociada a las dinámicas

\footnotetext{
${ }^{6}$ Sobre las condiciones en que permanecía la población ubicada en centros de detención, véase https:// www.elsalvador.com/fotogalerias/noticias-fotogalerias/coronavirus-albergues-de-migrantes/695754/2020/
} 
productivas, particularmente agropecuarias, que también se ha visto impactada por el contexto de emergencia sanitaria y las medidas gubernamentales de contención asociadas a esta. Destaca el caso costarricense pues recibe tanto población nicaragüense que se inserta en mercados laborales de producción agrícola, trabajo doméstico y construcción, como población indígena Ngäbe que se inserta sobre todo en el sector agrícola (Ugarte, 2020a), particularmente en la recolecta de café.

En relación con lo primero, el contexto de emergencia y las respuestas gubernamentales asociadas, tanto del gobierno nicaragüense como del costarricense, han generado una situación de alta vulnerabilidad para estas poblaciones, como ya se señaló antes. A las medidas de contención y cierre de fronteras se suman las prácticas de un conjunto de empresas agrícolas ubicadas sobre todo en la región Huetar Norte, que continúan contratando población migrante indocumentada en condiciones de explotación sin respetar las garantías laborales (Paniagua Arguedas, 2007; Rodríguez Echavarría \& Prunier, 2020; Segura Hernández \& Ramírez Mora, 2015), y con un alto nivel de riesgo ante la pandemia. Si bien la Presidencia de la República y los ministerios de Seguridad, Gobernación y Policía y Agricultura y Ganadería firmaron un decreto a finales de septiembre para multar a las empresas agropecuarias, agroexportadoras y agroindustriales que contrataran personas migrantes indocumentadas o sin trámite de regularización, no se han establecido acciones de seguimiento que permitan hacer cumplir la norma de forma cabal. ${ }^{7}$

Ante esta situación, a mediados de junio una alianza de organizaciones e instituciones emitió un comunicado llamando a las autoridades públicas a hacer cumplir las garantías y derechos de esta población, específicamente frente a las conocidas prácticas de explotación y vulneración de la agroindustria sobre las personas trabajadoras migrantes (Chacón, 2020a). Ante la inacción de las instancias respectivas y la continuidad en las malas prácticas laborales, a inicios de julio varias organizaciones emitieron un nuevo pronunciamiento en el que llamaron a elaborar y aprobar una ley para autorizar a la Inspección de Trabajo (instancia del Ministerio de Trabajo) a establecer sanciones directas a las empresas de la agroindustria que incumplieran la legislación laboral. Adicionalmente, el pronunciamiento subrayaba la preocupación por el aumento de casos de contagio en personas migrantes trabajadoras de estas empresas, asociado a las condiciones laborales y habitacionales en que se mantenía a los empleados (Chacón, 2020b).

El comportamiento del sector del servicio doméstico también ha develado la gran paradoja del migrante irregular o precario como trabajador indispensable. Quxabel Cárdenas, coordinadora de la Asociación Enlaces Nicaragüenses en Costa Rica, ha sostenido que la crisis del COVID-19 ha afectado a las mujeres migrantes y sus familias en Costa Rica, en tres sentidos: despidos sin respeto a los derechos laborales, reducción de las jornadas con bajas significativas en los ingresos, aumento de la carga de trabajo sin compensación en salario (particularmente para las trabajadoras de planta) (Mejía, 2020).

\footnotetext{
${ }^{7}$ Decreto Ejecutivo N 42406- MAG-MGP, que establecía que "las empresas de los sectores agropecuarios, agroexportadores o agroindustriales que contraten migrantes indocumentados o que no tengan en trámite su regularización, enfrentarían multas de entre dos y 12 veces un salario base" (Sistema Costarricense de Información Jurídica, 2020).
} 


\section{Apuntes sobre la agravación de los factores de expulsión migratoria}

\section{Centroamérica y la crisis permanente}

De acuerdo con Acuña González, "haber cerrado fronteras contuvo medianamente el virus, pero no la agudización de las vulnerabilidades para cientos de personas en contextos de movilidad 'confinada'” (Acuña González, 2020). La crisis económica global asociada al COVID-19 muestra impactos nacionales y locales en todo Centroamérica. En la Tabla 1 se sistematizan los principales indicadores socioeconómicos para los seis países de la región, así como los últimos datos disponibles hasta febrero 2021 en cuanto a su evolución por la emergencia sanitaria.

Cabe subrayar que los pronósticos de crecimiento negativo del producto interno bruto (PIB) para 2020 se agravaron a partir del segundo semestre, al prever severas recesiones de hasta $-8.6 \%$ o $-8.3 \%$ para El Salvador o Nicaragua respectivamente (Cepal, 2020b). Las cifras sobre pérdidas de empleo formal constituyen una variable sujeta a muchas variaciones según las fuentes. Hay que rescatar que la maquiladora especializada en producción textil y de material biomédico, generalmente instalada en zonas francas exentas de impuestos, es una de las principales generadoras de empleos para este país y ocupa en su mayoría fuerza de trabajo femenina. En Honduras, donde se estima en 150000 el número de trabajadores de maquila, se dieron despidos masivos y graves violaciones a los derechos laborales, como el conteo de días de vacaciones y feriados durante el cierre de las empresas por contingencia, todo permitido por la Secretaría del Trabajo de Honduras, según alertó el Centro de Información sobre Empresas y Derechos Humanos el 26 de marzo (Empresas pueden conceder a cuenta de vacaciones los días de la cuarentena, 2020). Además de ser ilegal, esta medida se mostró insostenible, ya que solo permitió posponer la suspensión de contrato a mitad de abril (el número de días de vacaciones de un obrero hondureño difícilmente cubre más de dos semanas). Al detener la producción en las maquilas y suprimir los magros salarios de miles de trabajadores (el salario mínimo es de 350 us\$ mensuales, apenas suficiente para cubrir la canasta básica, y con prestaciones de jubilación y salud muy bajas) fueron sobre todo mujeres las afectadas, y con ellas hogares monoparentales pobres que constituían, sin embargo, un sector de relativa estabilidad económica en comparación con otros del país (Torres Zelaya, 2020).

Sin embargo, queda muy claro que estas evaluaciones frágiles sobre empleo formal no reflejan la situación real de los mercados laborales centroamericanos, dada la alta proporción de empleos informales y precarios. Además de los trabajadores asalariados que han sido suspendidos sin prestaciones ni respeto de los derechos laborales básicos (muchas veces con la bendición de los gobiernos que privilegiaron el respaldo al sector empresarial), el número de personas cuya actividad económica bajó significativamente o se detuvo completamente es incalculable (por ejemplo, en sectores como el pequeño negocio, el transporte o los servicios). 
Tabla 1. Indicadores de desarrollo socioeconómico antes y después de la pandemia por COVID-19

\begin{tabular}{|c|c|c|c|c|c|c|c|c|}
\hline & \multicolumn{5}{|c|}{ Indicadores pre-COVID } & \multicolumn{3}{|c|}{ Indicadores de impactos del COVID } \\
\hline País & $\begin{array}{c}\text { Población } \\
\text { total } 2018 \\
\text { (a) }\end{array}$ & $\begin{array}{l}\text { Población } \\
\text { rural } 2018 \\
\text { (a) }\end{array}$ & $\begin{array}{c}\text { Población } \\
\text { menor de } \\
34 \text { años, } \\
2020 \text { (b) }\end{array}$ & $\begin{array}{c}\text { Porcentaje } \\
\text { de la po- } \\
\text { blación en } \\
\text { situación de } \\
\text { inseguridad } \\
\text { alimentaria } \\
\text { severa, } 2019 \\
\text { (c) }\end{array}$ & $\begin{array}{l}\text { Coeficiente } \\
\text { de Gini } \\
\text { (año más } \\
\text { reciente, } d \text { ) }\end{array}$ & $\begin{array}{c}\text { Evaluación } \\
\text { de baja del } \\
\text { PIB para } \\
2020 \text { (e;f) }\end{array}$ & $\begin{array}{l}\text { Pérdida de } \\
\text { empleos } \\
\text { formales } \\
\text { en } 2020 \\
\text {-meses- } \\
\text { (fuentes) }\end{array}$ & $\begin{array}{l}\text { Variación del } \\
\text { Îndice de Precios al } \\
\text { Consumidor (evo- } \\
\text { lución de los pre- } \\
\text { cios de una canasta } \\
\text { de bienes y servi- } \\
\text { cios representativa } \\
\text { del patrón de con- } \\
\text { sumo de cada país), } \\
\text { (enero 2019-enero } \\
\text { 2020, en \%. k) }\end{array}$ \\
\hline Guatemala & 17247849 & $\begin{array}{c}8440970: \\
48.9 \%\end{array}$ & $71.50 \%$ & 18.1 & $48.3(2014)$ & $\begin{array}{l}-3 \% \\
-4.1 \%\end{array}$ & & 5.24 \\
\hline Honduras & 9587522 & $\begin{array}{c}4040365: \\
42.1 \%\end{array}$ & $66.50 \%$ & 23.9 & $52.1(2018)$ & $\begin{array}{l}-5.8 \% \\
-6.1 \%\end{array}$ & $\begin{array}{l}182955, \\
\text { febrero-agos- } \\
\text { to }(\mathrm{g} ; \mathrm{h})\end{array}$ & 4.18 \\
\hline El Salvador & 6420746 & $\begin{array}{c}1793751: \\
27.9 \%\end{array}$ & $62 \%$ & 14.6 & $38.6(2018)$ & $\begin{array}{l}-5.4 \% \\
-8.6 \%\end{array}$ & $\begin{array}{l}73538 \text {, febre- } \\
\text { ro-junio (i) } \\
200000 \text { solo } \\
\text { en sector } \\
\text { textil (j) }\end{array}$ & 0.31 \\
\hline Nicaragua & 6465501 & $\begin{array}{c}2606772: \\
40.3 \%\end{array}$ & $63.20 \%$ & nd & $46.2(2014)$ & $\begin{array}{l}-6.3 \% \\
-8.3 \%\end{array}$ & nd & nd \\
\hline Costa Rica & 4999441 & $\begin{array}{c}1023354: \\
20.4 \%\end{array}$ & $52.40 \%$ & 5.4 & $48(2018)$ & $\begin{array}{l}-3.3 \% \\
-5.5 \%\end{array}$ & nd & 0.96 \\
\hline Panamá & 4176869 & $\begin{array}{c}1344157: \\
32.1 \%\end{array}$ & $57.30 \%$ & nd & 49.2 (2018) & $\begin{array}{c}-2 \% \\
-6.5 \%\end{array}$ & nd & nd \\
\hline
\end{tabular}

Fuente: a) http://www.fao.org/faostat

b) Cepal, 2019.

C) FAO, IFAD, UNICEF, WFP \& WHO, 2020

d) Banco Mundial, s. f. A manera de comparación, este índice que permite evaluar el nivel de desigualdad (más fuerte al acercarse a 100) es de 45.4 para México (2018), 41.1 para Estados Unidos (2016), 31.9 para Alemania (2016).

e) Nagovitch, 2020.

f) Cepal, 2020b.

g) Alarmante pérdida de empleos y cierre de empresas reporta el sector privado, 2020

h) Sector formal perdió más de 182 mil plazas de trabajo entre febrero y agosto, 2020.

i) Fundación Salvadoreña para el Desarrollo Económico y Social (Fusades), 2020.

j) Alemán, 2020.

k) http://www.secmca.org/ params $/ /$ ?scid $=0 \&$ cid=0\&data=IPC\&parent=Precios\&son=\%C3\%8Dndice $\% 20 \mathrm{de} \% 20$ precios\%20al\%20consumidor\&list 
A partir del 18 de mayo se reactivó paulatinamente el sector de las maquiladoras en Honduras, mientras que el proceso de reapertura económica a nivel nacional (anunciado a inicios de junio, bajo un formato progresivo y una división del país en tres regiones) conoció retrocesos a fase $1 \mathrm{o}$ incluso 0 en ciertas zonas, debido al aumento de los casos de contagio (Gonzalez et al., 2021). Igualmente, el plan de reapertura económica de El Salvador "Hacia la nueva normalidad", previsto con cinco etapas, empezó a ponerse en marcha el 24 de agosto, tras muchas tensiones entre el poder ejecutivo, la Corte Suprema, la Asamblea Legislativa y el Tribunal Constitucional acerca de la definición de un equilibrio entre el establecimiento de un estado de excepción que restringiera las libertades individuales y la necesidad de reactivar la economía.

Por otro lado, la Comisión Económica para América Latina y el Caribe (Cepal) pronostica una reducción de alrededor de $10 \%$ en las exportaciones desde Centroamérica para todo 2020, con fuertes disparidades según sectores y países. Pero en los cinco primeros meses de pandemia aumentaron para Costa Rica, Nicaragua, Honduras y Guatemala (únicos cuatro países de toda Latinoamérica en donde se dio este fenómeno) por la demanda de Estados Unidos de productos manufacturados de salud y protección personal y de productos agrícolas. Para El Salvador, las exportaciones de maquila cayeron $42.4 \%$ en el sector textil y $24 \%$ para el conjunto de los sectores productivos (Cepal, 2020a).

Como la mayoría de países con fuerte tradición migratoria, las economías centroamericanas son altamente dependientes de las remesas. Esta situación se refleja al comparar su contribución con otros indicadores significativos a nivel nacional (véase Tabla 2) y se nota particularmente para El Salvador, Honduras y Guatemala.

Tabla 2. Indicadores representativos de la contribución de las remesas para los principales países expulsores de migrantes de Centroamérica, 2019

\begin{tabular}{|c|c|c|c|}
\hline País & \% del PIB & \% de las exportaciones & $\begin{array}{c}\text { \% de la inversión extranjera directa } \\
\text { (IED) }\end{array}$ \\
\hline Guatemala & 13.7 & 105.3 & 1052.7 \\
\hline Honduras & 21.6 & 61.8 & 1081 \\
\hline El Salvador & 20.9 & 118 & 779.4 \\
\hline Nicaragua & 13.2 & 38 & 328 \\
\hline
\end{tabular}

Fuente: Cepal, 2020b.

A raíz de la emergencia sanitaria global se observó una disminución abrupta en el envío de remesas entre febrero y abril (por ejemplo, de $+10 \%$ a $-40 \%$ en comparación con el mismo mes del año anterior, para el caso de El Salvador [Cepal, 2020b]), pero volvieron a subir a partir de mayo hasta llegar a cifras récord en el caso de Guatemala, por ejemplo, con 1000 millones de dólares recibidos en concepto de remesas en el mes de julio de 2020 (Morales Rodas, 2020). Estas dinámicas consecutivas muestran dos tipos de reacciones (articuladas y no contradictorias) de los migrantes y sus familias frente a situaciones de crisis: en primer lugar, una reacción de precaución y disminución de los envíos hacia el lugar de origen, frente a la incertidumbre provocada por la pérdida de empleos y el desconocimiento de los impactos a mediano o largo plazo en el mercado laboral del país receptor; en segundo lugar, el mantenimiento 
y reactivación de los envíos, que se pueden explicar por mecanismos de resiliencia, solidaridad y continuidad de las actividades laborales para estos trabajadores esenciales de las llamadas "primeras líneas", a pesar de la crisis.

Finalmente, el carácter extractivista y dependiente de las economías centroamericanas debe ser subrayado para poder analizar los potenciales efectos de la actual crisis sanitaria y económica en términos de fronteras. En efecto, parece fundamental pensar la frontera desde la perspectiva de las desigualdades, las asimetrías y las fracturas socioeconómicas, con enfoque en comprender sus efectos en materia de exclusión, marginalización y violencia, como factores clave de las dinámicas recientes de migración y exilio de buena parte de la población centroamericana. En este sentido, resulta sugerente prestar atención a los modos de gobernanza política y económica que se manifestaron en plena pandemia. En Honduras, por ejemplo, las organizaciones de la sociedad civil y los movimientos de defensa del territorio, como el Consejo Cívico de Organizaciones Populares e Indígenas de Honduras (Copinh) o la Organización Fraternal Negra Hondureña (Ofraneh), denunciaron una forma de aprovechamiento de la crisis sanitaria por el gobierno de Hernández para censurar a la oposición y a las iniciativas de resistencia comunitarias o locales frente al despojo y la privatización de los recursos, mientras la colocación de capital extranjero se veía promovida a través de mecanismos poco transparentes y democráticos. El caso de la Zona de Empleo y Desarrollo Económico (ZEDE) de Roatán provocó particular indignación a inicios de octubre de 2020 (Vallejo Larios, 2020), ya que vino a demostrar nuevamente los lazos entre intereses políticos y económicos, los mecanismos de corrupción y la pérdida de soberanía, así como la conformación de territorios caracterizados por la "excepción" y la "extraterritorialidad" (Roux \& Geglia, 2019). El Estado hondureño tuvo un papel clave, pues es el que selecciona las zonas, impulsa la acumulación por despojo gracias a su capacidad de expropiación y, finalmente, impulsa mecanismos de privatización de ciertos sectores estratégicos (agricultura intensiva, turismo, maquiladoras, etcetéra) para cumplir con el objetivo de ser parte de las cadenas de valor de la economía global.

\section{La agudización de la vulnerabilidad y marginalización}

Los impactos de la emergencia sanitaria sobre el empleo y la cohesión social aparecen como especialmente graves en la juventud. La interrupción de los procesos educativos, la reducción de los ingresos familiares, la violencia doméstica y la dificultad de acceder a un empleo han afectado particularmente a la generación joven en países en los que representa una proporción muy importante de la población total, por ejemplo, $57 \%$ en países como Honduras y Guatemala, más de 10 puntos encima del promedio de América Latina y el Caribe.

La estructura demográfica de los países centroamericanos es un factor fundamental para tomar en cuenta a la hora de observar los impactos del COVID-19 en las dinámicas de fronteras. La población joven, en plena edad productiva y en situación de responsabilidad económica hacia familiares dependientes (niños y/o padres), ya se encontraba en desventaja laboral con respecto a la población económicamente activa antes de la crisis sanitaria (Sandoval García, 2017). Pero preocupa la profundización de la brecha laboral y el aumento del número de jóvenes marginalizados por la doble imposibilidad de una mejora de oportunidades. Sin estudio ni trabajo, esta categoría 
de población ve su nivel de desesperación socioeconómica dispararse: la pobreza, la desintegración familiar y la violencia de las pandillas conforman una combinación compleja de motivos para la migración hacia el Norte (Salazar Araya, 2017).

Por otro lado, el Programa Mundial de Alimentos de las Naciones Unidas ha alertado que "la pandemia de salud está impulsando el hambre y la inseguridad alimentaria" (Programa Mundial de Alimentos, 2020b). Además de grupos particularmente vulnerables como los haitianos o los venezolanos (que se encuentran en sus países o en espacios de movilidad por el exilio), el Programa Mundial de Alimentos de la onu llama particularmente la atención sobre la región del "corredor seco centroamericano", en donde las personas, que enfrentaban hambre en el periodo anterior a la pandemia, se encuentran ahora amenazadas por la pérdida de empleos y la temporada de huracanes, presión adicional sobre los sistemas de producción de subsistencia y de protección social. $^{8}$

Es de notar que la Organización de las Naciones Unidas para la Alimentación y la Agricultura (FAO, por sus siglas en inglés) reportó, a través de su herramienta de seguimiento y análisis de los preciso alimentarios, un importante aumento de precios de los granos básicos en todos los países de la región para abril de 2020: el maíz y el frijol negro experimentaron un aumento de $20 \%$ en El Salvador y $30 \%$ en Guatemala, por ejemplo, con respecto al mismo mes del año anterior. ${ }^{9}$ Este fenómeno fue causado tanto por el aumento de la demanda interna tras la aplicación de medidas de confinamiento, como por la fuerte demanda de exportaciones en el mercado global, lo que confirma la estrecha relación entre dependencia comercial de economías nacionales volcadas hacia el exterior e inseguridad alimentaria de una población que no logra satisfacer sus necesidades básicas.

En toda la región, el hambre se ha convertido en hambruna, particularmente en los tres países del norte, donde las banderas blancas empezaron a colgar en las ventanas de los mesones de los barrios populares o en casitas que bordan los paisajes del campo. Son familias que piden auxilio cuando niños, adultos o ancianos sufren por la falta de alimentos, al mismo tiempo que representan una protesta silenciosa en contextos de Estados ausentes y de gran angustia social. ${ }^{10}$ Otras manifestaciones del hambre fueron los bloqueos de carreteras, barricadas o rompimientos de toques de queda, como muestras de irritación social y de protestas espontáneas para exigir ayuda gubernamental en alimentos. ${ }^{11}$ Los índices de pobreza previos a la pandemia constituyen una variable que se agregó desde marzo a una aguda crisis de la economía y del empleo. La precariedad alimentaria se expresa tanto en el medio urbano - con grupos altamente marginados en búsqueda de ingresos al día y en la imposibilidad de cumplir con las medidas de cuarentena-, como en un medio rural (49\% de la población en Guatemala o $42 \%$ para Honduras; contra $20 \%$ para el conjunto de los países latinoamericanos) estructuralmente frágil, debilitado a niveles social y productivo por el deterioro ambiental, la expansión de los monocultivos y la expulsión del campesinado.

\footnotetext{
${ }^{8}$ Ver las estimaciones realizadas en el transcurso de la pandemia por diferentes programas internacionales de lucha contra el hambre para EI Salvador, Honduras y Guatemala (Programa Mundial de Alimentos, 2020a; Más de 1.6 millones de hondureños sufren inseguridad alimentaria por COVID-19, 2020; Acción contra el Hambre, 2020).

${ }^{9}$ http://www.fao.org/giews/food-prices/price-tool/es/

${ }^{10}$ Ver, por ejemplo, en El Salvador: Dada, 2020; Labrador, 2020; Barrera, 2020.

11 Ver, por ejemplo, en Honduras: Red de Solidaridad de la Maquila, 2019.
} 


\section{Estrategias de movilidad temporal y regional obstaculizadas: impactos en el sistema migratorio centroamericano}

Además de la dificultad para conseguir ingresos provenientes de empleos o actividades informales locales, parte de las economías familiares centroamericanas se han enfrentado a la imposibilidad de activar estrategias de migración regional temporal dado el cierre de fronteras con países vecinos. Estas tradicionales dinámicas de circulación y de movilidades cortas son fundamentales para la reproducción familiar en numerosos hogares centroamericanos, en donde la sobrevivencia depende de lógicas combinadas de actividades precarias en el lugar de residencia y actividades temporales en otros mercados laborales cercanos, a veces del otro lado de la frontera nacional. Si bien los lentes académico y mediático se enfocan muy a menudo en los mecanismos de resolución de los problemas de pobreza, violencia y desempleo por la migración internacional en dirección a Estados Unidos (por el carácter espectacular de las caravanas, por la implicación geopolítica para la relación de México con su vecino del norte, o bien por el efecto simbólico del cruce de la frontera GuatemalaMéxico en términos de rompimiento de un límite regional), es indispensable subrayar la importancia de las movilidades temporales y la relativa permeabilidad de las fronteras intrarregionales para comprender mejor los retos que enfrenta Centroamérica en tiempos del COVID-19. Estas formas de movilidad han sido una estrategia de larga data de poblaciones excluidas y precarizadas de la región ante los clivajes y conflictos históricos destacados antes. La interdependencia de los territorios se refleja particularmente en zonas fronterizas, donde la búsqueda de trabajos eventuales o la inserción a dinámicas comerciales regionales dan ritmo a desplazamientos frecuentes y dan lugar a un tejido socioeconómico que atraviesa fronteras desde generaciones.

En el caso de Nicaragua, la movilidad hacia El Salvador, Honduras y Guatemala, relativamente fácil en términos administrativos y económicos (por el Convenio Centroamericano de libre movilidad o CA-4), constituye un medio de inserción a los mercados laborales, más allá de la zona de residencia, que se integra en sistemas de recursos frágiles, donde la migración de corta distancia y corta duración permite reforzar las estrategias de resistencia (Prunier, 2018). La repartición de la fuerza de trabajo (diferentes miembros de la familia en diferentes espacios de movilidad) es sobre todo un mecanismo usado por familias de más bajos recursos económicos y sociales, que no cuentan con la posibilidad de invertir en la migración extrarregional. Dicho de otra manera, sin subestimar la importancia del exilio y de las lógicas de huida de los migrantes que deciden buscar empleo o pedir asilo en Estados Unidos, se quiere aquí insistir en otra cara de la realidad migratoria centroamericana, fuertemente afectada por la crisis sanitaria: la centralidad de los desplazamientos temporales a escala regional como recurso para mantenerse y reproducir la vida en el lugar de origen (educación, salud, vivienda). Por lo tanto, aunque ningún estudio sistematizado permite ahora medir la amplitud de los impactos de los cierres de fronteras nacionales a partir de marzo de 2020, se puede plantear la hipótesis de serios efectos para las economías familiares que anteriormente se apoyaban en mecanismos de pluriactividad y diversificación, tanto de las actividades como de los espacios del mercado laboral regional.

Se alienta a una lectura compleja de los sistemas migratorios, en donde no se pueden desvincular las escalas, los territorios productivos ni las distintas corrientes 
migratorias. De acuerdo con Gildas Simon, estos sistemas se definen como una "articulación dinámica de los espacios y campos migratorios en una escala geográfica amplia [...] que produce una construcción territorial a nivel regional, estructurada por las formaciones de estados y los efectos de los dispositivos reglamentarios" (traducción propia) de control de fronteras (Simon, 2008, p. 21). Desde esta perspectiva, se considera necesario entender de manera integrada a los impactos de la globalización en la constitución de mercados laborales y movilidades a escala centroamericana, y a la emergencia de flujos migratorios que involucran otros espacios, en particular México y Estados Unidos. La estrecha relación entre las dos dinámicas de fronteras (intrarregionales y extrarregionales) es un elemento esencial para comprender el sistema migratorio centroamericano, ya que las movilidades temporales y circulatorias de tipo Sur-Sur no están desvinculadas de las estrategias de migración hacia el Norte, tanto a nivel de trayectorias individuales como familiares.

\section{Conclusiones}

Las líneas de frontera en la región son múltiples y entrecruzadas, tanto nacionales y administrativas como productivas, sociales, políticas y espaciales, y han provocado, a lo largo de la historia de la región, intensos movimientos de colonización agraria, poblamiento y circulación. Entender la profundidad histórica de los ciclos migratorios permite relacionar los recientes flujos hacia Estados Unidos - en su dimensión de respuesta a contextos de violencia y de migración forzada (Devia Garzon et al., 2016; Faret, 2020; Winton, 2017; Wolf, 2020) - con ciclos internos o regionales anteriores. Es notable el caso de Honduras, por ejemplo, cuyos ciclos migratorios -bananero, agrario y maquilero- también están vinculados con la violencia estructural del modelo económico de desarrollo vigente en la zona, vía la agricultura intensiva, la concentración de las tierras y la industrialización para la exportación (Equipo de Reflexión, Investigación y Comunicación Compañía de Jesús ERIC-SJ et al., 2020).

La emergencia de la crisis sanitaria ha evidenciado que la región se configura como un espacio multiterritorial (Haesbaert, 2011), al subrayar los diferentes modos de gobernanza política y de control de las circulaciones en las fronteras del Estadonación, pero también las asimetrías socioeconómicas que influyen en el acceso al trabajo, a los ingresos, a los alimentos, a las redes, etcétera. En el contexto pandémico, distintas acepciones de frontera (escalas y tipos de límites o asimetrías) tienen que ser puestas en perspectiva, y considerar el lugar de la región en las dinámicas de exclusión/integración por la globalización. Vemos como de forma paralela al estricto control de la movilidad de trabajadores y exiliados en las fronteras nacionales se han profundizado lógicas de extractivismo, dependencia e inserción desigual en el capitalismo mundial (Smith, 2020), que se traducen en una competencia aguda por inversiones extranjeras, al ofrecer al capital las "mejores" condiciones (Central America Data, 2020) (salarios bajos, derechos laborales casi inexistentes, ventajas fiscales, zonas económicas de excepción, entre otras). Entre el cierre de fronteras para la circulación de cierto tipo de personas y la apuesta hacia un desarrollo basado en la venta de mano de obra barata, las líneas de fractura y de asimetría socioterritorial parecen haberse acentuado en este último año. 
La crisis se evidencia, como en otros momentos de la historia de la región, más como una oportunidad de las élites políticas para agilizar la implementación de medidas acorde a sus intereses (de control de las movilidades y de la población particularmente de actores subalternos contestatarios-, de sostenimiento de los flujos de circulación de capitales y mercancías, de reforma económica y laboral, etcétera), que como una situación de inestabilidad para el proyecto hegemónico. Por otra parte, se percibe que la sociedad civil, de forma organizada o espontánea, mantiene una importante capacidad de agencia y un fuerte potencial de resistencia frente a las desigualdades históricas y contemporáneas que estructuran la región. Ya sea desde estructuras institucionales o militantes, en movimientos locales, redes sociales o las mismas caravanas migrantes, se ven acciones dirigidas a la adaptación y a la autoprotección (por ejemplo, la tendencia del flujo de remesas, que muestra gran capacidad de gestión para hacer efectiva la respuesta de "llevar dinero al bolsillo" de la poblaciones más afectadas), a la denuncia de discursos xenofóbicos y reducidamente sanitarios o del aprovechamiento de la crisis por algunos gobiernos para censurar formas de oposición e iniciativas de resistencia comunitarias o locales frente al despojo y la privatización de los recursos.

Finalmente, con la instalación de las medidas de emergencia y declaratorias de excepción se manifestaron bajo una luz nueva las tendencias autoritarias y corruptas de ciertos regímenes centroamericanos: la colusión entre Estado, narcotráfico y crisis de los derechos humanos en Honduras (Equipo de Reflexión, Investigación y Comunicación ERIC-SJ, s. f.; Vásquez, 2020), la militarización del territorio, el carácter neopopulista y las posturas anticonstitucionales del presidente Bukele en El Salvador (Monterrosa, 2020; Valencia \& Sánchez, 2020), o la deriva despótica de la pareja Ortega-Murillo en Nicaragua (Collombon, 2020). Resulta importante insistir en los efectos de la epidemia en la evolución de las formas de gobierno autoritario en la región (López Bernal, 2020), en términos de gestión de las fronteras y de la movilidad humana. Desde la criminalización de la movilidad precaria y trabajadora hasta la aplicación de medidas de cuarentena inhumanas para personas deportadas, pasando por el rechazo de connacionales varados en el exterior, y amenazas a derechos fundamentales, ${ }^{12}$ se puede presagiar la profundización de los factores de exclusión e injusticia social en países tradicionalmente expulsores de migrantes.

Pero el autoritarismo, el control y la amenaza a los derechos más básicos vuelven a ser enfrentados con estrategias de movilidad colectivas como forma de visibilizar la diáspora y generar medidas de autoprotección (Salazar Araya, 2019). En la madrugada del 1 de octubre de 2020, un grupo de migrantes hondureños salió de San Pedro Sula para conformar una nueva caravana con rumbo a Estados Unidos. Ingresaron al territorio guatemalteco por dos cruces fronterizos (Corinto y Agua Caliente), a pesar del despliegue policial-militar que buscaba impedirles el paso. El gobierno de Guatemala rápidamente dio el tono, al presentar el paso indocumentado por su territorio como un atentado sanitario: prohibió a los transportistas subir a los migrantes hondureños, promovió la denuncia de personas migrantes y diseminó un discurso que los relacionaba con el riesgo de contagio. Sin esperar, el gobierno mexicano, a través de la Secretaría de Gobernación, difundió el boletín n. 366, en el

\footnotetext{
12 Por ejemplo, en Honduras, con la represión de las protestas en contra del gobierno de Juan Orlando Hernández (Red de Solidaridad de la Maquila, 2019) y con la amenaza a los derechos económicos, sociales y culturales (Coalición Contra la Impunidad, 2020).
} 
que recordó las sanciones de multa o prisión para toda persona que "ponga en peligro de contagio la salud de otro". En ambos países se desplegaron fuerzas armadas, y en diferentes puntos del territorio guatemalteco se impulsaron acciones para disolver a los grupos de migrantes, controlarlos, deportarlos y alentarlos al retorno voluntario. Las organizaciones de la sociedad civil, observadores y académicos interpretan estas medidas como formas de intimidación, discriminación y criminalización de las poblaciones migrantes. ${ }^{13}$

El 15 de enero de 2021 se formó otra caravana desde el mismo punto de partida. Más de 3500 personas se organizaron a través de las redes sociales y pronto se unieron más hasta llegar a alrededor de 9000 . El día 16, a pesar de la presencia de fuerzas de seguridad, cruzaron la frontera con Guatemala por el cruce de El Florido, para ser bloqueados al día siguiente a unos $60 \mathrm{~km}$ de distancia, en la localidad de Chiquimula. En el camino se enfrentaron al uso brutal de la fuerza y vieron disuelto su esfuerzo, con un trasfondo de miedo y criminalización que asocia la ilegalización del cuerpo migrante con la amenaza sanitaria. ${ }^{14}$

La consolidación de la nueva lógica geopolítica que se rige por la externalización de las fronteras apareció entonces con más claridad que nunca (Sandoval García, 2020). El combate contra la migración indocumentada en Estados Unidos ya no se juega (no solamente) en la discusión sobre el muro, ni tampoco siquiera en la frontera sur de México. Se define ahora siempre más al sur, en Centroamérica: la lógica de externalización se despliega en la frontera entre Honduras y Guatemala (Salazar Araya, 2017), que tradicionalmente constituía una zona de circulación porosa. La política exterior de Estados Unidos, pero también la de México, se refleja en este nuevo rol que asume Guatemala como policía migratoria en el camino hacia el Norte, a cambio de programas de cooperación y proyectos de desarrollo (Villafuerte Solís, 2018; Toussaint \& Garzón, 2017). En este contexto, la pandemia ofrece un pretexto perfecto para obstruir los flujos bajo la justificación de la contención sanitaria.

Recientemente, el gobierno de Biden parece haber querido mostrar un giro en la política de su predecesor. Mediante un decreto firmado el 6 de febrero (EFE, 2021; Guimón, 2021), puso fin al acuerdo de "tercer país seguro" con Guatemala, Honduras y El Salvador, al tiempo que afirmó que quería seguir una política de gestión migratoria "ordenada" con estos estados. Firmado en julio de 2019 con Guatemala (en los hechos, nunca se había establecido con los otros dos países), el Acuerdo de Cooperación de Asilo (ACA) permitía deportar a migrantes hondureños o salvadoreños a este país donde teóricamente podrían encontrar condiciones satisfactorias para solicitar asilo.

En este contexto, el desplazamiento de la frontera dentro de la propia Centroamérica (Washington Office on Latin America [wOLA], 2020) y la militarización de los espacios de tránsito justificada por la lucha contra la pandemia constituyen dos elementos nuevos y preocupantes.

Las fronteras conforman límites cuya transgresión por las migraciones es el reflejo de la inserción de las sociedades a las dinámicas globales. Se hace evidente el carácter desigual, violento y urgente de la necesidad de desplazamiento que se puede anticipar para los próximos meses/años, a raíz de la profundización de las condiciones de pobreza, explotación y marginalización en los lugares de origen.

\footnotetext{
${ }^{13}$ Ver los comunicados de octubre 2020, por parte del Colectivo de Observación y Monitoreo de Derechos Humanos en el Sureste Mexicano (Programa de Asuntos Migratorios de la Universidad Iberoamericana Ciudad de México, s. f.).

${ }^{14}$ Ver el Conversatorio lucha migrante (Álvarez Velasco, 2021).
} 


\section{Agradecimientos}

Este artículo se inscribe en el marco del Proyecto (In)movilidad en las Américas, Nodo Centroamérica (https://www.inmovilidadamericas.org/) y del Laboratorio Mixto Internacional MESO-Movilidades, gobernanza y recursos en la cuenca mesoamericana (https://meso.hypotheses.org/).

\section{Referencias}

Acción contra el Hambre. (2020, 15 de junio). La COVID-19 duplica el número de personas sin alimentos en Guatemala. https://www.accioncontraelhambre.org/es/ te-contamos/actualidad/la-covid-19-duplica-el-numero-de-personas-sin-alimentos-en-guatemala

Acuña González, G. (2020). Movilidades en suspenso, Blog COVID-1919 desde la Historia Aplicada. https:/ / historiaaplicada.org/movilidades-en-suspenso/

AFP. (2020, 2 de junio). ops dice que trasmisión de COVID-19 en Nicaragua "está muy difícil de controlar". Semanario Universidad. https://semanariouniversidad.com/ mundo/ops-dice-que-trasmision-de-COVID-19-en-nicaragua-esta-muy-dificil-decontrolar/

Alarmante pérdida de empleos y cierre de empresas reporta el sector privado. (2020, 1 de octubre). El Heraldo. https://www.elheraldo.hn/economia/1412252-466/alarmantep\%C3\%A9rdida-de-empleos-y-cierre-de-empresas-reporta-el-sector-privado

Alemán, U. (2020, 23 de junio). Industria textil perdió 20000 empleos durante cuarentena. El Mundo. https://diario.elmundo.sv/industria-textil-perdio-20000-empleos-durante-cuarentena/

Alto Comisionado de las Naciones Unidas para los Refugiados (ACNUR). (2020, 3 de abril). ACNUR adapta sus programas en Costa Rica ante el COVID-19 para seguir brindando asistencia. https://www.acnur.org/noticias/press/2020/4/5e87554f4/acnuradapta-sus-programas-en-costa-rica-ante-el-covid-19-para-seguir-brindando.html

Álvarez Velasco. S. (2016). ¿Crisis migratoria contemporánea? Complejizando dos corredores migratorios globales. Ecuador Debate, (97), 155-171. http://hdl.handle.net/10469/12140

Álvarez Velasco, S. (Coord.). (2020a). (In)Movilidad en las Américas. COVID-19. https:/ / www.inmovilidadamericas.org/

Álvarez Velasco, S. (Coord.). (2020b). Cierre de fronteras e hipervigilancia. (In) Movilidad en las Américas. https://www.inmovilidadamericas.org/cierre-fronteras

Álvarez Velasco, S. (Coord.). (2020c). Suspensión del derecho al asilo y refugio. (In) Movilidad en las Américas. https://www.inmovilidadamericas.org/suspension-asilo

Álvarez Velasco, S. (Coord.). (2020d). El Salvador. (In)Movilidad en las Américas. https://www.inmovilidadamericas.org/el-salvador

Álvarez Velasco, S. (Coord.). (2021, 22 de enero). Conservatorio lucha migrante. (In) Movilidad en las Américas. https://www.inmovilidadamericas.org/post/conservatorio-lucha-migrante 
Angulo Barredo, J. I. (2008). De las montañas de Chiapas al Soconusco, La Selva, Cancún, y ahora a Estados Unidos. Las prácticas migratorias de los campesinos indígenas de Chiapas. En D. Villafuerte \& M. C. García (Coords.), Migraciones en el sur de México y Centroamérica (pp. 323-342). Miguel Ángel Porrúa/Unicach.

Armijo Canto, M. N. \& Benítez Manaut, R. (2016). Vulnerabilidad y violencia en el corredor Centroamérica-México-Estados Unidos. Ecuador Debate, (97), 103-121. http://hdl.handle.net/10469/12137

Baby-Collin, V., Cortes, G., Faret, L. \& Sassone, S. (2009). Une approche comparée des circulations migratoires latino-américaines: Les cas bolivien et mexicain. En G. Cortes \& L. Faret (Dirs.), Les circulations transnationales: Lire les turbulences migratoires contemporaines (pp. 91-108). Armand Colin.

Banco Mundial. (s. f.). Índice de Gini. https://datos.bancomundial.org/indicador/ SI.POV.GINI? end $=2018 \&$ start $=2018 \&$ view $=$ bar

Barrera, C. (2020, 18 de marzo). "Si me quedo en casa, me muero de hambre". El faro. https://elfaro.net/es/202003/ef_foto/24133/

Baumeister, E. (1994). El café en Honduras. En H. Pérez \& M. Samper (Coords.), Tierra, café y sociedad: ensayos sobre la historia agraria centroamericana (pp. 437-94). Flacso Costa Rica.

Baumeister, E. (2001). Las reformas agrarias en Centroamérica: un balance de sus resultados al finalizar los años 90. En H. Clemens \& R. Ruben (Coords.), Nueva ruralidad y política agraria: una alternativa neoinstitucional para Centroamérica. Nueva Sociedad/Centro de Estudios para el Desarrollo Rural/Vrije Universiteit te Amsterdam.

Bourgois, P. (2009). Recognizing invisible violence: A thirty-year ethnographic retrospective. En B. Rylko-Bauer, L. M. Whiteford \& P. Farmer (Eds.), Global health in times of violence. School for Advanced Research Press.

Cáceres, G., Quintanilla, J. \& Rauda, N. (2020, 25 de marzo). La cuarentena del Triángulo Norte no logra detener los vuelos de deportados. El Faro. https://elfaro. net/es/202003/centroamerica/24177/La-cuarentena-del-Tri\%C3\%A1ngulo-Norte-no-logra-detener-los-vuelos-de-deportados.htm

Cajina, J. (2020, 24 de julio). El calvario de los nicaragüenses varados en el extranjero por la pandemia. Deutsche Welle. https://www.dw.com/es/el-calvario-de-los-nicarag\%C3\% BCenses-varados-en-el-extranjero-por-la-pandemia/a-54302230

Cañada, E. (2011). Migraciones en Centroamérica: en la médula de un cambio estructural. Encuentro, (90), 34-49. https://doi.org/10.5377/encuentro.v44i90.599

Castro, Y. (2020). Migrantes frente a la refronterización y la hipervigilancia en el control migratorio durante Covid-19. Lecciones aprendidas del primer conversatorio "Cierre de fronteras e hipervigilancia". En Clacso, (Trans) Fronteriza: (In) movilidades en las Américas y COVID-19 (Núm. 3. Boletín del Grupo de Trabajo Fronteras: movilidades, identidades y comercios, pp. 54-61). https://www. clacso.org/wp-content/uploads/2020/12/V3_TransFronteriza_N3.pdf

Central America Data. (2020, 2 de octubre). La lucha por la inversión extranjera en 2021. https://www.centralamericadata.com/es/article/home/IED_Lo_que_se_espera_en_2021 
Chacón, V. (2020a, 16 de junio). Pandemia no es excusa para ignorar los derechos humanos. Semanario Universidad. https://semanariouniversidad.com/pais/pandemiano-es-excusa-para-ignorar-los-derechos-humanos/

Chacón, V. (2020b, 1 de julio). Sociedad civil y academia exigen respeto a los derechos de las personas trabajadoras migrantes. Semanario Universidad. https://semanariouniversidad.com/pais/sociedad-civil-y-academia-exigen-respeto-a-los-derechos-de-las-personas-trabajadoras-migrantes/

Chavarría, D. (2020, 27 de mayo). Ministro de Salud: "Nuestro principal riesgo es el alto nivel de circulación del virus en Nicaragua". Interferencia. https://radios. ucr.ac.cr/2020/05/interferencia/ministro-de-salud-nuestro-principal-riesgo-es-el-alto-nivel-de-circulacion-del-virus-en-nicaragua/

Coalición contra la Impunidad. (2020). Los derechos económicos, sociales y culturales (DESC), el espacio cívico y la defensa de los derechos humanos en el marco de la emergencia sanitaria (Boletín núm. 3). https://eric-sj.org/wp-content/uploads/2021/01/BC_ BOLETIN-3_LOS-DESC.pdf

Collombon, M. (2020, 14 de junio). COVID-19 au Nicaragua: la pandémie sous régime autoritaire. COVIDAM: la COVID-19 dans les Amériques. https://covidam.institutdesameriques.fr/covid-19-au-nicaragua-la-pandemie-sous-regime-autoritaire/

Comisión Económica para América Latina y el Caribe (Cepal). (2019). Anuario Estadístico de América Latina y el Caribe 2018. https://www.cepal.org/es/publicaciones / 44445-anuario-estadistico-america-latina-caribe-2018-statistical-yearbook-latin

Comisión Económica para América Latina y el Caribe (Cepal). (2020a, 6 de agosto). Los efectos del COVID-19 en el comercio internacional y la logística (Informe especial núm. 6). https://www.cepal.org/sites/default/files/publication/files/45877/ S2000497_es.pdf

Comisión Económica para América Latina y el Caribe (Cepal). (2020b, septiembre). Estudio económico de Centroamérica y la República Dominicana en 2019 y perspectivas para 2020. https://repositorio.cepal.org/bitstream/handle/11362/46026/1/ S2000637_es.pdf

Dada, C. (2020, 2 de julio). El hambre blanca. El Faro.

De Genova, N. (2017). The incorrigible subject: mobilizing a critical geography of (Latin) America through the autonomy of migration. Journal of Latin American Geography, 16(1), 17-42. https://doi.org/10.1353/lag.2017.0007

Demyk, N. (2007). Café et pouvoir en amérique centrale. Études rurales, (180), 13754. https://doi.org/10.4000/etudesrurales.8540

Devia Garzon, C. A., Ortega Avellaneda, D. A. \& Niño Pérez, J. J. (2016). Violencia estructural en el triángulo norte centroamericano. Logos, Ciencia y Tecnología, 7(2), 105-114. https://dialnet.unirioja.es/servlet/articulo?codigo=6470468

EFE. (2021, 6 de febrero). Gobierno de Biden suspende el acuerdo de "tercer país seguro" con El Salvador, Guatemala y Honduras. Sin embargo.mx. https://www.sinembargo. $\mathrm{mx} / 06-02-2021 / 3935038$

Eguren, J. \& S. Hernández Bonilla, S. (Eds.). (2019). Caravanas de migrantes: manifestaciones de la compleja realidad centroamericana (Colección Obimid vol. 6). Observatorio Iberoamericano sobre Movilidad Humana, Migraciones y Desarrollo/ Comillas Universidad Pontifica/Red Jesuita con Migrantes Ca\&Na/Univer- 
sidad Rafael Landívar, IDGT. https://eric-sj.org/migracion/caravanas-de-migrantes-manifestaciones-de-la-compleja-realidad-centroamericana/

El Faro/AFr. (2020, 14 de abril). Guatemala: $75 \%$ de un vuelo de deportados dio positivo a coronavirus. El Faro. https://elfaro.net/es/202004/centroamerica/24287/Guatemala-75-de-un-vuelo-de-deportados-dio-positivo-a-coronavirus.htm

Empresas pueden conceder a cuenta de vacaciones los días de la cuarentena. (2020, 26 de marzo). La Prensa. https://www.laprensa.hn/honduras/1367570-410/empresas-coronavirus-vacaciones-cuarentena-feriados-honduras-

Equipo de Reflexión, Investigación y Comunicación ERIC-SJ. (s. f.). Se profundiza crisis de derechos humanos debido a la gestión de la pandemia Covid-19. https:/ / eric-sj.org/ $\mathrm{dd}-\mathrm{hh} /$ se-profundiza-crisis-de-derechos-humanos-debido-a-la-gestion-de-la-pandemia-covid-19/

Equipo de Reflexión, Investigación y Comunicación ERIC-SJ. (2020, 26 de marzo). Ante la deportación desde los Estados Unidos y México de personas migrantes durante la propagación de COVID-19. https://eric-sj.org/noticias/ante-la-deportacion-desde-los-estados-unidos-y-mexico-de-personas-migrantes-durante-la-propagacion-de-COVID-19/

Equipo de Reflexión, Investigación y Comunicación Compañía de Jesús ERIC-SJ, González Cerdeira, Y., Ayala, M., Cardoza, G., Posadas, O., Hernández, E. \& Mejía, J. (2020). Ciclos migratorios en Honduras (Migración y Desarrollo, Colección 9). Observatorio de Migraciones Internacionales en Honduras/Facultad Latinoamericana de Ciencias Sociales/Universidad Nacional Autónoma de Honduras. https://eric-sj.org/wp-content/uploads/2020/07/FOLLETO-FLACSO-9. pdf

Euraque, D. A. (1996). Reinterpreting the Banana Republic: region and state in Honduras, 1870-1972. University of North Carolina Press.

Farah, D. (2012). Central American gangs: changing nature and new partners. Journal of International Affairs, 66(1), 53-67. https://servicioar.pbidi.unam.mx/cgi-bin/ ezpmysqlssl.cgi?url=https://www.jstor.org/stable/24388251

Faret, L. (2015). El Salvador. En G. Simon (Coord.), Dictionnaire géohistorique des migrations internationales (pp. 550-554). Armand Colin.

Faret, L. (2020). Migrations de la violence, violence en migration. Les vulnérabilités des populations centraméricaines en mobilité vers le Nord. Revue Européenne des Migrations Internationales, 36(1), 31-52. https://doi.org/10.4000/remi.14393

Food and Agriculture Organization (FAO), International Fund for Agricultural Development (IFAD), United Nations International Children's Emergency Fund (UNICEF), World food Programme (wFP) \& World Health Organization (wHO). (2020). The state of food security and nutrition in the world 2020. Transforming food systems for affordable healthy diets). http://www.fao.org/documents/card/en/c/ ca9692en

Fundación Salvadoreña para el Desarrollo Económico y Social (Fusades). (2020). Informe de coyuntura social 2019-2020. http://fusades.org/publicaciones/ ICS_19_20.pdf

Galtung, J. (1969). Violence, peace, and peace research. Journal of Peace Research, 6(3), 167-191. https://www.jstor.org/stable/422690?seq=1 
Garibo, M. (2016). Migración centroamericana en tránsito por México en el marco de la externalización de la frontera estadounidense: Plan Sur y Plan Frontera Sur. Punto Cunorte (3), 71-102. http://www.cunorte.udg.mx/puntocunorte/revistas/3/ articulos/migracion-centroamericana-en-transito-por-mexico-en-el-marco-de-la

Gatica López, G. (2018). Aportes de las personas migrantes y refugiadas a la creación de riqueza en Costa Rica. Revista Rupturas, 8(1), 63-91 https://doi.org/10.22458/ rr.v8i1.1974

Granados Chaverri, C. (1986). Geopolítica en Centroamérica (Cuadernos Políticos, núm. 46), 74-89. Ediciones Era. http://www.cuadernospoliticos.unam.mx/cuadernos/contenido/CP.46/CP46.8.CarlosGranadosChaverri.pdf

Gonzalez, E., Harrison, C., Hopkins, K., Horwitz, L., Nagovitch, P., Sonneland, H. K. \& Zissis, C. (2021, 10 de febrero). El coronavirus en América Latina. AS/COA. https://www.as-coa.org/articles/el-coronavirus-en-america-latina

Guimón, P. (2021, 6 de febrero). Biden suspende los acuerdos de "tercer país seguro" con El Salvador, Honduras y Guatemala. El País. https://elpais.com/internacional/2021-02-07/biden-suspende-los-acuerdos-de-tercer-pais-seguro-con-el-salvador-honduras-y-guatemala.html

Haesbaert, R. (2011). El mito de la desterritorialización. Del "fin de los territorios" a la multiterritorialidad. Siglo xxI.

Honduras se blinda para frenar ingreso de nicaragüenses por COVID-19. (2020, 15 de mayo). Infobae. https://www.infobae.com/america/agencias/2020/05/15/honduras-se-blinda-para-frenar-ingreso-de-nicaraguenses-por-covid-19/

Instituto Guatemalteco de Migración. (2020). Estadísticas de retornados (vía aérea y vía terrestre. http://igm.gob.gt/estadisticas/

La impaciente espera de los migrantes en Choluteca, Honduras. (2020, 27 de abril). Criterio.hn. https://criterio.hn/la-impaciente-espera-de-los-migrantes-en-choluteca-honduras/

Labrador, G. (2020, 7 de junio). Una carta de auxilio desde Soyapango. El faro. https://elfaro.net/es/202006/el_salvador/24514/Una-carta-de-auxilio-desde-Soyapango.htm

León, A. \& Salazar, S. (2016). Del cerro al norte. Historia y memoria en la migración campesina hondureña. En C. Sandoval García (Ed.), Migraciones en América Central. Políticas, territorios y actores (pp. 3-23). Editorial UCR. http://www.editorial. ucr.ac.cr/ciencias-sociales/item/2162-migraciones-en-america-central-politicas-territorios-y-actores.html

López Bernal, C. G. (2020). Autoritarismo y coronavirus. Maestría en historia aplicada. https://historiaaplicada.org/autoritarismo-y-coronavirus/

Martínez Velazco, G. (1993). Migración y poblamiento guatemalteco en Chiapas. Mesoamerica, 14(25), 73-100. https://dialnet.unirioja.es/servlet/articulo?codigo $=4011053$

Más de 1.6 millones de hondureños sufren inseguridad alimentaria por COVID-19. (2020, 2 de julio). La Tribuna. https://www.latribuna.hn/2020/07/02/mas-de-1-6-millones-de-hondurenos-sufren-inseguridad-alimentaria-por-COVID-19/

Medina, L. (2013). Una interfaz transfronteriza compleja. El caso del golfo de Fonseca: El Salvador, Honduras y Nicaragua. LiminaR, 11(2), 54-69. http://www.scielo.org.mx/scielo.php?script=sci_abstract\&pid=S1665-80272013000200004\&lng=es\&nrm=iso 
Mejía, A. (2020, 16 de junio). Covid-19 impacta a mujeres trabajadoras migrantes en Costa Rica. La Nueva Prensa. https://lanuevaprensacr.com/covid-19-impacta-a-mujeres-trabajadoras-migrantes-en-costa-rica/?fbclid=IwAR3JTp-cMl2WeOFIyL1P3UBy-wFN9QI7KONAUx2vRnslpdIGikGKzgktCe8

Migración refuerza medidas sanitarias en fronteras y aeropuerto por Coronavirus. (2020, 23 de enero). La Página. https://lapagina.com.sv/nacionales/migracion-refuerza-medidas-sanitarias-en-fronteras-y-aeropuerto-por-coronavirus/

Migrantes violentados por autoridades en medio de emergencia nacional. (2020, 28 de abril). Conexihon. http://www.conexihon.hn/index.php/mirada-al-sur/1523-migrantes-violentados-por-autoridades-en-medio-de-emergencia-nacional

Miranda, H. \& Murillo, A. (2020, 31 de marzo). Migración masiva de haitianos y africanos compromete cierre de fronteras en pandemia COVID-19. Semanario Universidad. https://semanariouniversidad.com/pais/migracion-masiva-de-haitianos-y-africanos-compromete-cierre-de-fronteras-en-pandemia-COVID-19/

Mitchell, J. C. (1985). Towards a situational sociology of wage-labour circulation. En R. M. Prothero \& M. Chapman (Eds.), Circulation in Third World Countries (pp. 30-53). Routledge.

Monterrosa, L. A. (2020, abril). Del 9-F al 9-M: el autoritarismo en tiempos del coronavirus. Envío Digital, (457). https://www.envio.org.ni/articulo/5760;\%20 https://www.envio.org.ni/articulo/5805

Morales Gamboa, A. (2005). Migraciones y territorios pobres en la globalización: nuevas territorialidades de la exclusión social en América Central. Flacso Costa Rica. https://ccp. ucr.ac.cr/noticias/migraif/pdf/morales.pdf

Morales Gamboa, A. (2015). Regionalismo de los migrantes y dinámicas territoriales en América Central. IdeAs. Idées d'Amériques, (6). https://doi.org/10.4000/ ideas. 1141

Morales Gamboa, A., Kandel, S., Ortiz, X., Diaz, O. \& Acuña, G. (2011). Trabajadores migrantes y megaproyectos en América Central. Programa de las Naciones Unidas para el Desarrollo/Universidad Centroamericana "José Simeón Cañas". https://www.sv.undp.org/content/el_salvador/es/home/library/poverty/trabajadores-migrantes-y-megaproyecto-en-america-central.html

Morales Rodas, S. (2020, 17 de agosto). Migrantes: remesas baten récord, sin que esto signifique más desarrollo para Guatemala. Prensa Libre. https://www.prensalibre. com/guatemala/migrantes/migrantes-remesas-baten-record-sin-que-esto-signifique-mas-desarrollo-para-guatemala/

Muñoz, D. (2020, 28 de abril). COVID-19 recrudece el drama de nicaragüenses en el exilio. Semanario Universidad. https://semanariouniversidad.com/pais/covid-19-recrudece-el-drama-de-nicaraguenses-en-el-exilio/

Murillo, A. (2020, 12 de abril). Costa Rica refuerza su frontera mientras ve con temor la política sanitaria de Nicaragua. El País. https://elpais.com/internacional/2020-04-12/ costa-rica-refuerza-su-frontera-mientras-ve-con-temor-la-politica-sanitaria-de-nicaragua.html

Nagovitch, P. (2020, 16 de junio). Latin American GDP dives as COVID-19 deepens. AS/ COA. https://www.as-coa.org/articles/latin-american-gdp-dives-covid-19-deepens 
OPS reitera advertencias a Nicaragua sobre manejo de la pandemia. (2020, 19 de agosto). Elmundo.cr. https://www.elmundo.cr/mundo/ops-reitera-advertencias-a-nicaragua-sobre-manejo-de-la-pandemia/

Organización Internacional para las Migraciones (OIM). (2020, 18 de abril). Emergency tracking: COVID19 Pandemic Migrant Receiving Stations (MRS) Situation Report \#2, 2-9 April 2020, Panama. United Nations Office for the Coordination of Humanitarian Affairs. https://reliefweb.int/report/panama/emergency-tracking-covid19-pandemic-migrant-receiving-stations-mrs-situation-report-2

Paniagua Arguedas, L. (2007). Situación sociolaboral de la población nicaragüense en Costa Rica. Revista Ciencias Sociales (117-118), 57-7. https://repositorio.iis.ucr. ac.cr/handle/123456789/628

Peña, J. (2020, 26 de marzo). Costa Rica and Panama loosen borders for thousands of U.S.bound migrants. Center for Inmigration Studies. https://cis.org/Pena/Costa-Rica-and-Panama-Loosen-Borders-Thousands-USBound-Migrants

Pérez Brignoli, H. \& Samper, M. (Comps.). (1994). Tierra, café y sociedad: ensayos sobre la historia agraria centroamericana. Flacso.

Pomareda, F. (2020a, 1 de julio). Migración: en espera de "los varados" en medio de la pandemia. Semanario Universidad. https://semanariouniversidad.com/pais/ migracion-en-espera-de-los-varados-en-medio-de-la-pandemia/

Pomareda, F. (2020b, 9 de julio). Migrantes extracontinentales continúan cruzando por Paso Canoas en la frontera sur. Semanario Universidad. https:/ / semanariouniversidad. $\mathrm{com} /$ pais/migrantes-extracontinentales-continuan-cruzando-por-paso-canoas-en-la-frontera-sur/

Programa de Asuntos Migratorios de la Universidad Iberoamericana Ciudad de México. (s. f.). Frontera Sur. http:/ / caravanamigrante.ibero.mx/frontera-sur

Programa Mundial de Alimentos. (2020a, 8 de junio). La tormenta tropical Amanda impacta gravemente la seguridad alimentaria de 340,000 salvadoreños. https://es.wfp. org/noticias/Amanda-impacta-seguridad-alimentaria-de-340000-salvadorenos

Programa Mundial de Alimentos. (2020b, 29 de julio). El hambre aumenta a medida que los casos de la COVID-19 se disparan en América Latina. https://es.wfp.org/noticias/hambre-aumenta-a-medida-casos-covid-19-se-disparan-America-Latina-Caribe

Prothero, R. M. \& Chapman, M. (1985). Circulation in Third World countries. Routledge.

Prunier, D. (2017). Repensar los retornos a través de los sistemas de movilidad en Centroamérica. El caso de Nicaragua. LiminaR, 15(1), 177-191. http://www.scielo. org.mx/scielo.php?script=sci_arttext\&pid=S1665-80272017000100177

Prunier, D. (2018). Nuevas territorialidades rurales en Nicaragua. De la dispersión migratoria a la gestión de los sistemas de recursos familiares. En O. Hoffmann \& A. Morales Gamboa (Coords.), El territorio como recurso: movilidad y apropiación del espacio en México y Centroamérica (pp. 191-214). Flacso/Universidad Nacional de Costa Rica/Institut de recherche pour le développement. https://hal. archives-ouvertes.fr/hal-02043299/document

Red de Solidaridad de la Maquila. (2019, 30 de julio). Ola de protestas contra el gobierno se expande en Honduras. https://www.maquilasolidarity.org/es/ola-de-protestascontra-el-gobierno-se-expande-en-honduras 
Reyes, E. (2020, 27 de abril). Giammattei llamó "vuelo maldito" a un avión con guatemaltecos deportados. Crónica. https://cronica.com.gt/giammattei-llamo-vuelo-maldito-a-un-avion-con-guatemaltecos-deportados/

Rodríguez Echavarría, T. \& Prunier, D. (2020). Extractivismo agrícola, frontera y fuerza de trabajo migrante: La expansión del monocultivo de piña en Costa Rica. Frontera Norte, 32, 1-25. https://fronteranorte.colef.mx/index.php/fronteranorte/article/view/1983

Roux, H. \& Geglia, B. (2019). ¿Excepción o continuismo? Nuevos enclaves: poder e infraestructura en Honduras. Iztapalapa. Revista de Ciencias Sociales y Humanidades 40(87), 17-43. http://dx.doi.org/10.28928/ri/872019/atc1/rouxh/gegliae

Salazar Araya, S. (2017). Circular el territorio migrante. Producción social de la migración centroamericana en tránsito por México: frontera, albergue y desaparición [Tesis doctoral]. Universidad Iberoamericana. https:/ $/ \mathrm{mx}$.antropotesis.alterum.info/? $\mathrm{p}=8230$

Salazar Araya, S. (2019, enero-julio). Las caravanas migrantes como estrategias de movilidad. Iberoforum. Revista de Ciencias Sociales de la Universidad Iberomericana, 14(27). 111-144. https://ibero.mx/iberoforum/27/pdf/ESPANOL/Caravanas-migrantes-como-estrategias-de-movilidad-Salazar.pdf

Sampó, C. (2013). Violence in Central America: Maras in El Salvador, Guatemala and Honduras. Estudios de Seguridad y Defensa (2). https://www.researchgate.net/ publication/308627226_Violencia_en_Centroamerica_Las_Maras_en_El_Salvador_Guatemala_y_Honduras

Sandoval García, C. (2017). Demandas ciudadanas de jóvenes residentes en barriadas populares en Centroamérica. Un estudio exploratorio regional. Universidad de Costa Rica. https://vinv.ucr.ac.cr/catedrahumboldt/images/catedratico-humboldt-2017-1-p.pdf

Sandoval García, C. (Ed.). (2020). Puentes, no muros. Contribuciones para una política progresista en migraciones. Clacso México/Fundación Rosa Luxemburg. http:// biblioteca.clacso.edu.ar/clacso/se/20200327054129/Puentes-no-muros.pdf

Sector formal perdió más de 182 mil plazas de trabajo entre febrero y agosto. (2020, 1 de octubre). La Prensa. https://www.laprensa.hn/economia/1412313-410/sector-formal-pierde-plazas-honduras-enero-febrero

Segura Hernández, G. \& Ramírez Mora, K. (2015). Entre surcos de piña: resistiendo el tiempo esclavo en el monocultivo. Revista Reflexiones, 94(2), 11-23. https:// revistas.ucr.ac.cr/index.php/reflexiones/article/view/25472/25722

Simon, G. (2008). La planète migratoire dans la mondialisation. Armand Colin.

Sistema Costarricense de Información Jurídica. (2020, 16 de junio). Procedimiento para acceder al régimen de excepción para la regularización migratoria de las personas trabajadoras de los sectores agropecuario, agroexportador o agroindustrial. $N^{\circ}$ 42406-MAGMGP. Procuraduría General de la República. http://www.pgrweb.go.cr/scij/ Busqueda/Normativa/Normas/nrm_texto_completo.aspx?param1=NRTC\&nValor1=1\&nValor2=91673\&nValor3=121118\&strTipM=TC

Smith, N. (2020). Desarrollo desigual. Naturaleza, capital y la producción del espacio. Traficantes de sueño.

Tarrius, A. (2000). Leer, describir, interpretar las circulaciones migratorias: conveniencia de la noción de territorio circulatorio. Los nuevos hábitos de la identidad. Relaciones, 21(83), 37-66. https://biblat.unam.mx/es/revista/rela- 
ciones-colmich-zamora/articulo/leer-describir-interpretar-las-circulaciones-migratorias-conveniencia-de-la-nocion-de-territorio-circulatorio-los-nuevos-habitos-de-la-identidad

Torres Zelaya, G. (2020, 3 de abril). Una proveedora de Nike encabeza las masivas suspensiones laborales en las maquilas de Honduras. El Salto. https://www.elsaltodiario.com/coronavirus/una-proveedora-de-nike-encabeza-las-masivas-suspensiones-laborales-en-las-maquilas-de-honduras

Toussaint, M. \& Garzón, M. (2017). El Proyecto Mesoamérica: ¿éxito o fracaso? Límites de la cooperación de México hacia Centroamérica. EntreDiversidades, (8), 15-52. https://doi.org/10.31644/ED.8.2017.a01

Ugarte, O. (2020a, 21 de mayo). Gobierno y oIM se reunirán en Zona Sur para atender a indígenas migrantes. Semanario Universidad. https://semanariouniversidad. $\mathrm{com} /$ pais/gobierno-y-oim-se-reuniran-en-zona-sur-para-atender-a-indigenas-migrantes/

Ugarte, O. (2020b, 5 de junio). Área de salud de Los Chiles prohíbe atender migrantes indocumentados sin presencia de Fuerza Pública o Migración. Semanario Universidad. https://semanariouniversidad.com/pais/area-de-salud-de-los-chiles-prohibe-atender-migrantes-indocumentados-sin-presencia-de-fuerza-publica-o-migracion/

Valencia, A. \& Sánchez, D. (2020, 5 de octubre). Política de seguridad pública en El Salvador: nada nuevo bajo el sol. El Faro. https://elfaro.net/es/202010/columnas/24885/Pol\%C3\%ADtica-de-seguridad-p\%C3\%BAblica-en-El-Salvador-nada-nuevo-bajo-el-sol.htm?fbclid=IwAR2kst_GJbyy8ujlCdMKGr4RMPUFPrgsHmcAOiktat-SoAOiJH9RINF9pU0;

Vallejo Larios, M. (2020, 7 de octubre). ZEDE en Honduras: reseña de una ilegalidad nefasta. Confidencial HN. https://confidencialhn.com/zede-en-honduras-resena-de-una-ilegalidad-nefasta/

Varela, A. (2015). La "securitización" de la gubernamentalidad migratoria mediante la "externalización" de las fronteras estadounidenses a Mesoamérica. Con-temporánea, (4), 1-17. https://con-temporanea.inah.gob.mx/node/108\#_ftn18

Vásquez, D. (2020, mayo-junio). Honduras en el abismo. Nueva Sociedad, (287). https:// nuso.org/articulo/honduras-en-el-abismo/

Villafuerte Solís, D. (2018). Seguridad y control geopolítico: crónica de la iniciativa para la prosperidad del Triángulo Norte de Centroamérica. Revista CS, (24), 91118. https://doi.org/10.18046/recs.i24.2506

Wallace, A. (2020, 21 de mayo). Coronavirus: "El gobierno de Nicaragua está tratando de esconder los muertos”. BBC News. https://www.bbc.com/mundo/noticias-america-latina-52716064

Washington Office on Latin America (wolA). (2020, 26 de octubre). Organizaciones de la sociedad civil denuncian la externalización de la frontera por parte del Departamento de Seguridad Nacional de los Estados Unidos (DHS) en Guatemala, se exige una investigación inmediata. https://www.wola.org/es/2020/10/dhs-externalizacion-frontera/

Winton, A. (2017). Movilidad y supervivencia: un estudio exploratorio sobre desplazamiento por violencia en el Norte de Centroamérica y el sur de México. El Colegio de la Frontera Sur. https://www.academia.edu/33678831/Movilidad_y_Supervivencia_Un_es- 
tudio_exploratorio_sobre_desplazamiento_por_violencia_en_el_Norte_de_ Centroam\%C3\%A9rica_y_el_sur_de_M\%C3\%A9xico

Wolf, S. (2020). La migración forzada desde el Triángulo Norte de Centroamérica. Impulsores y experiencias. Centro de Investigación y Docencia Económicas. https:// www.academia.edu/43533209/La_migraci\%C3\%B3n_forzada_desde_el_ Tri\%C3\%A1ngulo_Norte_de_Centroam\%C3\%A9rica_Impulsores_y_experiencias

Delphine Marie Prunier

Francesa. Doctora en geografía por la Universidad París Diderot. Actualmente es investigadora en el Instituto de Investigaciones Sociales de la UNAM. Es miembro del Laboratorio Mixto Internacional LMI-MESO "Movilidad, gobernanza y recursos en la cuenca mesoamericana" y del Grupo Clacso "Fronteras: movilidades, identidades y comercios". Es miembro del Sistema Nacional de Investigadores, nivel 1. Líneas de investigación: migraciones internacionales, dinámicas de movilidad, circulación y retorno, mercados laborales, agricultura y ruralidad en América central y en México. Publicación reciente: Prunier, D. (2021). Conflictos territoriales y territorios de los conflictos. ¿Cómo los movimientos sociales interactúan con el espacio? Geopolitica(s), 12(1), 77-98. https://doi.org/10.5209/geop.68992

\footnotetext{
Sergio Salazar

Costarricense. Doctor en antropología social por la Universidad Iberoamericana de México (2017). Docente de la Escuela de Ciencias Políticas (UCR) e investigador del Centro de Investigaciones y Estudios Políticos de la Universidad de Costa Rica. Líneas de investigación: democracia en Centroamérica, políticas de seguridad y democratización en Centroamérica, migración centroamericana en tránsito, modelos punitivos y políticas penitenciarias en Costa Rica, y población penal juvenil en Costa Rica. Publicación reciente: Salazar Araya, S. (2020). Violence and value in the migratory passage through Central America: the Cadereyta massacre (2012) and the struggle to have the bodies returned. Violence: an international journal, 1(2), 221-241. https://doi. org/10.1177\%2F2633002420970965
} 